Review

\title{
Bimetallic Nanoparticles: Enhanced Magnetic and Optical Properties for Emerging Biological Applications
}

\author{
Pannaree Srinoi, Yi-Ting Chen, Varadee Vittur, Maria D. Marquez and T. Randall Lee * (D) \\ Department of Chemistry and the Texas Center for Superconductivity, University of Houston, Houston, \\ TX 77204-5003, USA; psrinoi@uh.edu (P.S.); ychen75@uh.edu (Y.-T.C.); varadee148@hotmail.com (V.V.); \\ mdmarquez2@uh.edu (M.D.M.) \\ * Correspondence: trlee@uh.edu; Tel.: +1-713-743-2724
}

Received: 9 April 2018; Accepted: 27 June 2018; Published: 9 July 2018

\begin{abstract}
Metal nanoparticles are extensively studied due to their unique chemical and physical properties, which differ from the properties of their respective bulk materials. Likewise, the properties of heterogeneous bimetallic structures are far more attractive than those of single-component nanoparticles. For example, the incorporation of a second metal into a nanoparticle structure influences and can potentially enhance the optical/plasmonic and magnetic properties of the material. This review focuses on the enhanced optical/plasmonic and magnetic properties offered by bimetallic nanoparticles and their corresponding impact on biological applications. In this review, we summarize the predominant structures of bimetallic nanoparticles, outline their synthesis methods, and highlight their use in biological applications, both diagnostic and therapeutic, which are dictated by their various optical/plasmonic and magnetic properties.
\end{abstract}

Keywords: bimetallic nanoparticles; optical/plasmonic properties; magnetic properties; biological applications

\section{Introduction}

The synthesis and properties of metallic nanoparticles (NPs) has been extensively studied over decades, not only because of their unique properties, but also because of their potential applications in catalysis, electronics, optoelectronics, information storage, biosensors, and surface-enhanced Raman spectroscopy (SERS) [1-10]. Nanoparticles can exist as common structural elements or composites, and they have a wide functional diversity compared to bulk materials. The physical and chemical properties of metallic nanoparticles are mostly determined by the following parameters: size, shape, and composition [11,12]. Therefore, controlling these parameters is extremely important in tailoring the properties of the nanoparticles. Particular emphasis has recently been placed on controlling the shape because it allows the fine-tuning of optical properties with a greater versatility than can be achieved otherwise. Only recently has it become possible to control the shape of metal nanoparticles synthesized in solution, leading to the development of numerous synthetic methods [13-16]. For example, Murphy et al. developed a seed-mediated growth method to prepare gold nanorods and nanowires with controllable aspect ratios; these nanomaterials offer potential applications in optical sensing and as interconnects in nanoelectronics [17]. Xia and co-workers demonstrated a hot solution approach based on the polyol process for the large-scale synthesis of silver nanobars and nanorice particles, where the surface plasmon resonance can be tuned from the visible to near-infrared (NIR) spectral regions [18]. Additionally, Yamauchi et al. prepared bimetallic, magnetic Ni-Co (core-shell) nanoparticles under microwave irradiation [19]. 
Currently, procedures to fabricate various types of metal nanoparticles with excellent control over their size and shape are well-established [20]. However, the applicability of single-component metal nanoparticles is restricted by their limited properties. To overcome these limitations, metal nanoparticles can be modified through the construction of bimetallic architectures consisting of two distinct metals. These composite bimetallic nanoparticles exhibit fascinating properties that can be dramatically different from those of the corresponding single-component particles; these properties include the enhancement of plasmonic properties in Au-based alloy nanoparticles, enhanced magnetic properties in magnetic materials, or enhanced optical and magnetic properties in multifunctional nanoparticles, such as AuFe. These properties arise from both the electronic and structural effects of the bimetallic structures [21-23].

Bimetallic nanoparticles have played an important role in tuning the surface plasmon band, enhancing the stability and dispersion of nanoparticles, and regulating the magnetic and optical properties. Since these properties are strongly dependent on the structure and composition of the nanomaterials, the synthesis of bimetallic nanoparticles with accurately controlled structures and compositions is a worthwhile objective. For example, it has been demonstrated that the surface plasmon resonance of hollow bimetallic Au@Ag core-shell nanoparticles can be readily tuned by controlling the Ag:Au ratio in the replacement reaction [24]. In addition, $\mathrm{AuCu}$ nanoparticles have been used to prepare atomically ordered intermetallic nanocrystals by controlling the diffusion of $\mathrm{Cu}$ into $\mathrm{Au}$; this strategy provides a new avenue to fabricate unique bimetallic nanoparticles [25]. Separate studies have demonstrated the synthesis of CoAu bimetallic nanoparticles via chemical reduction, offering enhanced magnetic performance with little or no surface oxidation, which can lead to applications in magnetic resonance imaging [26].

In this review, we give a brief description of the optical and magnetic properties exhibited by bimetallic nanoparticles followed by an overview of the fundamental and technical approaches used for the synthesis, characterization, and processing of bimetallic nanoparticles, summarized in Figure 1. In addition, examples of selected biological applications, such as diagnostic applications as well as therapeutic use of bimetallic nanoparticles are discussed in the context of their plasmonic and magnetic properties.

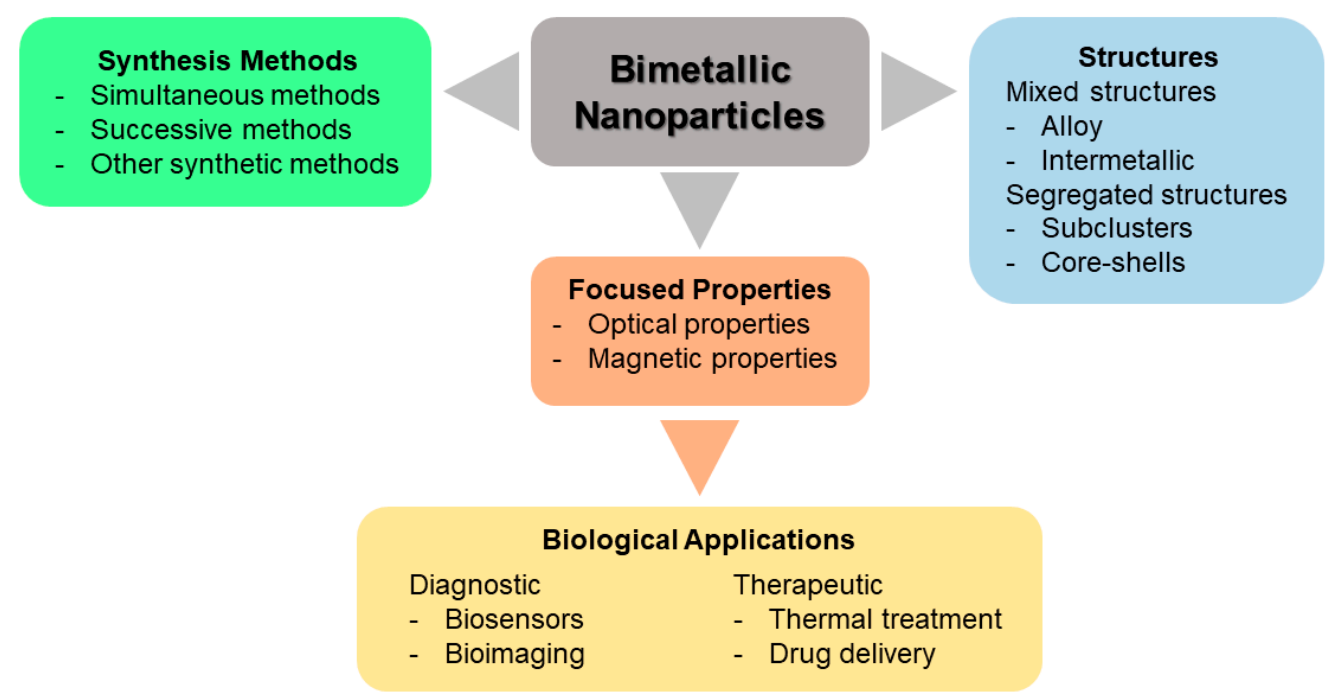

Figure 1. The synthesis and properties of bimetallic nanoparticles for biological applications.

\section{Optical and Magnetic Properties of Bimetallic Nanoparticles for Biological Applications.}

The unique optical and magnetic properties of bimetallic nanoparticles render them attractive for use in biological applications. One of the most interesting optical properties of noble metal nanoparticles, such as gold, silver, and copper, is the localized surface plasmon resonance 
(LSPR) $[27,28]$. Surface plasmon resonance occurs when the frequency of incident light matches the collective oscillation of surface electrons in the conduction band of the metal, as illustrated in Figure 2. Moreover, the LSPR extinction band can be tuned by varying the size, shape, and composition of the nanoparticles [29]. Furthermore, noble metal bimetallic nanoparticles exhibit strong plasmon resonances that can be controlled by varying the composition of the metals in the nanostructures [30].

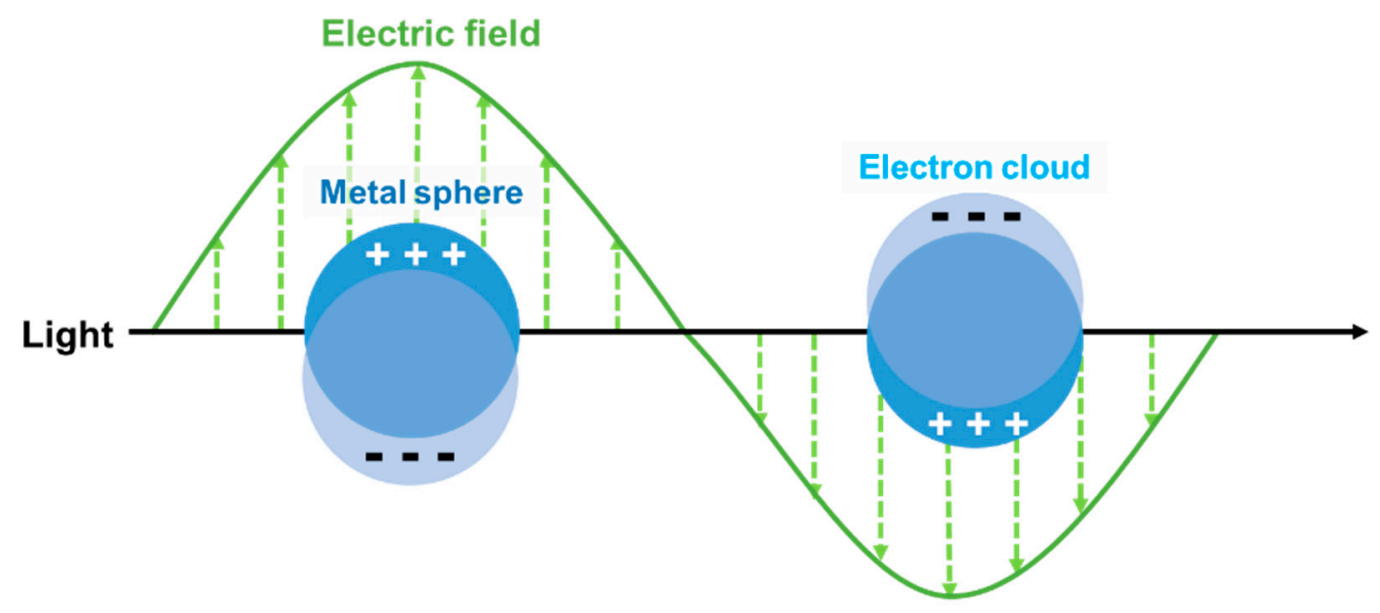

Figure 2. Localized surface plasmon oscillations in noble metal nanoparticles.

Over the past several years, there has been increasing interest in utilizing the LSPR of nanoparticles for biomedical applications such as biosensors, drug-delivery devices, cell imaging, diagnostics, and therapeutics [31-34]. Specifically, surface enhanced Raman scattering (SERS) has been used in biological applications due to SERS being highly effective in the near-infrared (NIR) region, where the signal from Raman scattering is greater than autofluorescence from surrounding tissue [35]. By varying the composition and structure of bimetallic nanoparticles, the optical resonances can be tuned over a broad range of wavelengths (e.g., UV-vis to NIR). Perhaps most important are optical resonances in the NIR region, which includes wavelengths between 800 and $1200 \mathrm{~nm}$, and is referred to as the "Tissue Transparency Window", where such light can penetrate both water and human tissue [36].

Similarly, the magnetic component of bimetallic nanoparticles provides them with unique nanomagnetism that allows for control of the motion of the particles in addition to offering magnetic spin behavior, which is critical in magnetic detection techniques, imaging, and thermal treatment methods [37]. Magnetic nanoparticles are typically characterized by the following physical characteristics: magnetization $(M)$, coercivity $\left(\mathrm{H}_{\mathrm{c}}\right)$, and magnetocrystalline anisotropy constant $(\mathrm{K})$. Figure 3 illustrates the fundamental magnetic properties of magnetic nanoparticles: saturation magnetization $\left(\mathrm{M}_{\mathrm{s}}\right)$, remanent magnetization $\left(\mathrm{M}_{\mathrm{r}}\right)$, and the coercivity $\left(\mathrm{H}_{\mathrm{c}}\right)$. When used in biological applications, the ability to manipulate the magnetic properties, such as saturation magnetization $\left(\mathrm{M}_{\mathrm{s}}\right)$, relaxation, and the size of the magnetic nanoparticles are critical parameters [37]. Saturation magnetization is the maximum magnetization value exhibited by the material, where the magnetic moments of the particles align with the direction of an applied external field. Relaxation can be categorized as Nèel relaxation and Brownian relaxation, where the former arises from spin-spin relaxation within the particles and the latter from the mechanical rotation of the particles [37]. Nèel relaxation dominates when the size of the particle is less than a single domain size and when the size of the nanoparticle is small; it is the critical factor for magnetic hyperthermia applications. On the other hand, Brownian relaxation dominates for larger particles and sizes greater than a single domain size; moreover, it is the critical factor in thermal applications [37,38]. 


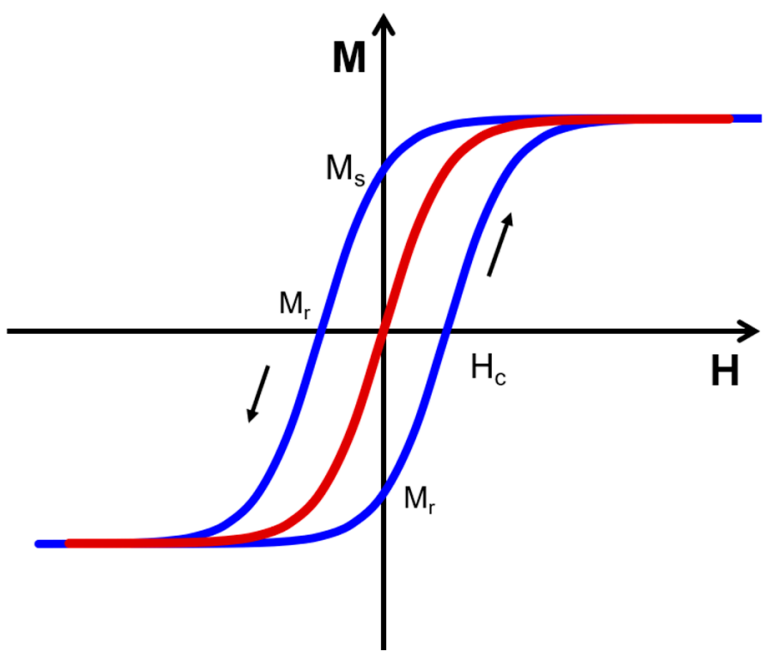

Figure 3. Schematic illustration of a magnetization hysteresis loop (blue) which shows the change in magnetization as a function of an applied magnetic field. A non-hysteretic magnetic curve (red) is representative of superparamagnetic behavior.

In general, higher saturation magnetization gives higher relaxation rates for magnetic resonance imaging (MRI), higher heat emission rates for magnetic hyperthermia treatments, and stronger translational attractive forces for magnetic separation [37,39]. Bimetallic alloys consisting of $3 \mathrm{~d}$ metals (e.g., $\mathrm{FeCo}$ ) exhibit a high magnetic moment and have been reported to have the highest saturation magnetization values (e.g., Ms $\sim 148 \mathrm{emu} / \mathrm{g}$ ) [40]. Furthermore, the combination of $3 \mathrm{~d}$ metals with $4 \mathrm{~d}$ or $5 \mathrm{~d}$ metals, which exhibit strong spin-orbital coupling, have been reported to enhance magnetic moments and enlarge anisotropy [41]. When the size of the nanoparticles is smaller than a single domain size, the nanoparticles exhibit superparamagnetic behavior. Superparamagnetic behavior in nanoparticles arises from the fast flipping of the magnetic moment of each nanoparticle, which at certain temperatures leads to a zero net magnetic moment [42]. Superparamagnetic nanoparticles exhibit no magnetism in the absence of a magnetic field; this unique property can be used to transport and deliver the nanoparticles to their targets.

\section{Classification and Synthesis of Bimetallic Nanoparticles}

\subsection{Classification of Bimetallic Nanoparticles}

It has been reported that heterogeneous bimetallic nanoparticles have more intriguing properties than the corresponding single component metal nanoparticles owing to their tunable chemical and physical properties [43]. The properties of bimetallic nanoparticles can be tuned by adjusting composition, atomic ordering, morphology, and size. Although bimetallic nanoparticles consist of only two different metals, there are still many types of possible structures. In terms of structure, bimetallic nanoparticles can be broadly classified into two types, as shown in Figure 4: mixed structures (Figure $4 a, b$ ) and segregated structures (Figure 4c-f). In terms of atomic ordering, the bimetallic nanoparticles can be further categorized into four types: alloy, intermetallic, subclusters, and core-shells [44]. 


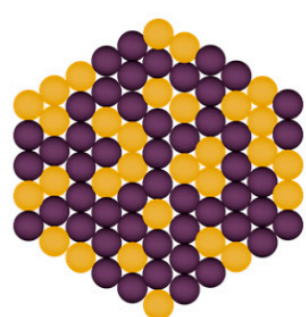

a

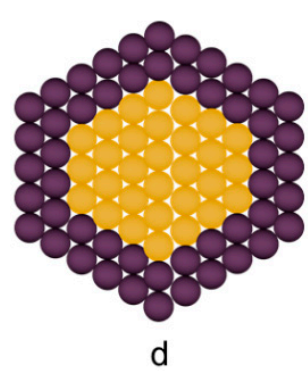

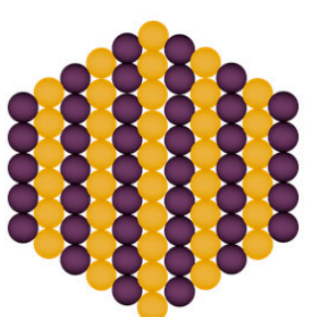

b

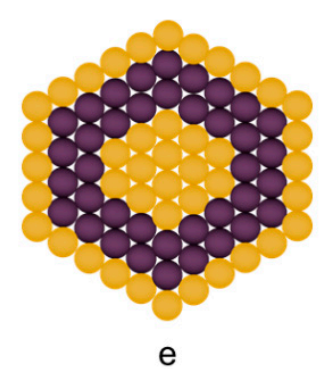

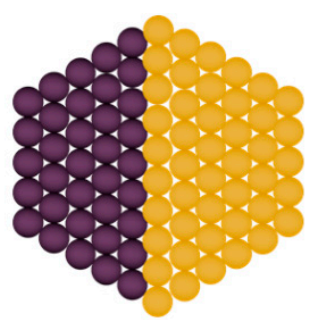

C

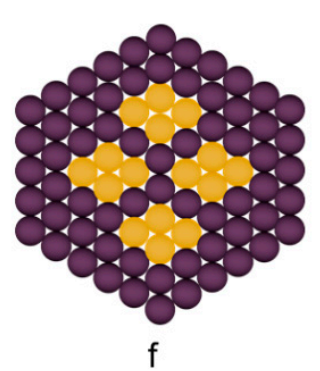

Figure 4. Types of bimetallic nanoparticles: (a) alloyed, (b) intermetallic, (c) subclusters, (d) core-shell, (e) multi-shell core-shell, and (f) multiple core materials coated by a single shell material. Yellow and purple spheres represent two different kinds of metal atoms. Adapted with permission from ref. [45]. Copyright 2008 American Chemical Society.

The nature of the atomic ordering in the two types of structures, with similar atomic ratios and compositions, plays an important role on the overall properties of the materials. The atomic ordering of mixed structures can be random (Figure 4a) or have an ordered configuration (Figure 4b). An example of a mixed structure with random arrangement is the alloyed structure, while an example of an ordered arrangement is the intermetallic structure. Alloyed nanoparticles are composed of nanocrystals in which the two metals are randomly mixed; while in intermetallic structures, the two metals are mixed in an ordered way. Solid solution structures occur when one metal dissolves in a different metal in the solid state. Solid solution structures can be further divided into substitutional and interstitial. Substitutional structures form when the size of the two metal atoms is similar, allowing metal atoms of one material to replace metal atoms of the second material in regular lattice sites. Whereas, if there is a dramatic size difference between the metal atoms, the smaller atom will position itself between the larger atoms to form an interstitial structure [46]. On the other hand, segregated structures are composed of two separate components with a shared interface, subcluster structure (Figure 4c), or a metal core surrounded with a second metal, core-shell structure (Figure 4d) [47]. Subcluster structures, in which two metals are exposed to the nanoparticle's environment, have also been defined as having a Janus configuration [48]. Unlike mixed structures, segregated structures are achieved in multi-step reactions in which the second metal is added once the first metal has formed an initial structure. Examples of segregated structures include the core-shell structure (Figure 4d), the multi-shell core-shell structure, in which the shells are in an alternating arrangement, similar to onion rings (Figure 4e), or the multiple small cores coated by a single shell (Figure 4f) $[45,49,50]$. Various synthetic strategies used for the formation of all types of atomically ordered structures are discussed in the following section.

Similar to organic chemical reactions, the concept of thermodynamic and kinetic control can be applied to the synthesis of metal nanoparticles [51]. For example, thermodynamic and kinetic control for the shape-controlled synthesis of nanoparticles is illustrated in Figure 5a [51]. The thermodynamically most stable product (i.e., the structure with the lowest Gibbs free energy, shape II) is considered the thermodynamic product, while the structure formed from the reaction pathway with the lowest activation energy $\left(\mathrm{E}_{\mathrm{a}}\right)$ is considered the kinetic product. Changing the reaction conditions, such as the temperature, can lead to thermodynamic or kinetic control. However, 
for multicomponent or hybrid particles, such as bimetallic nanoparticles, incorporation of the second metal complicates control beyond the simple analysis made for single-component particles. Several factors influence the structure of nanoalloys including the relative strengths of metal-metal bonds, the surface energy of bulk materials, relative atomic sizes, charge transfer, and specific electronic/magnetic effects [45]. Taking into consideration the different factors that influence structure and order, the synthesis of multicomponent nanoparticles can be better described by a set of continuous reactions, as shown in Figure $5 b$. In the continuous reaction pathway, the thermodynamic product is still the most thermodynamically stable (i.e., the product located at the global minimum). However, kinetic products can still be present if the energy of the reaction is insufficient to overcome the activation energy barrier in each step (i.e., the products located at the local minima), making temperature an important factor in determining the direction of the reaction [51]. Furthermore, Wang et al. provide a thorough review of thermodynamic and kinetic control in the synthesis of nanoparticles including their growth, etching, assembly, and shape control by using geometric analysis and logical deduction [52].
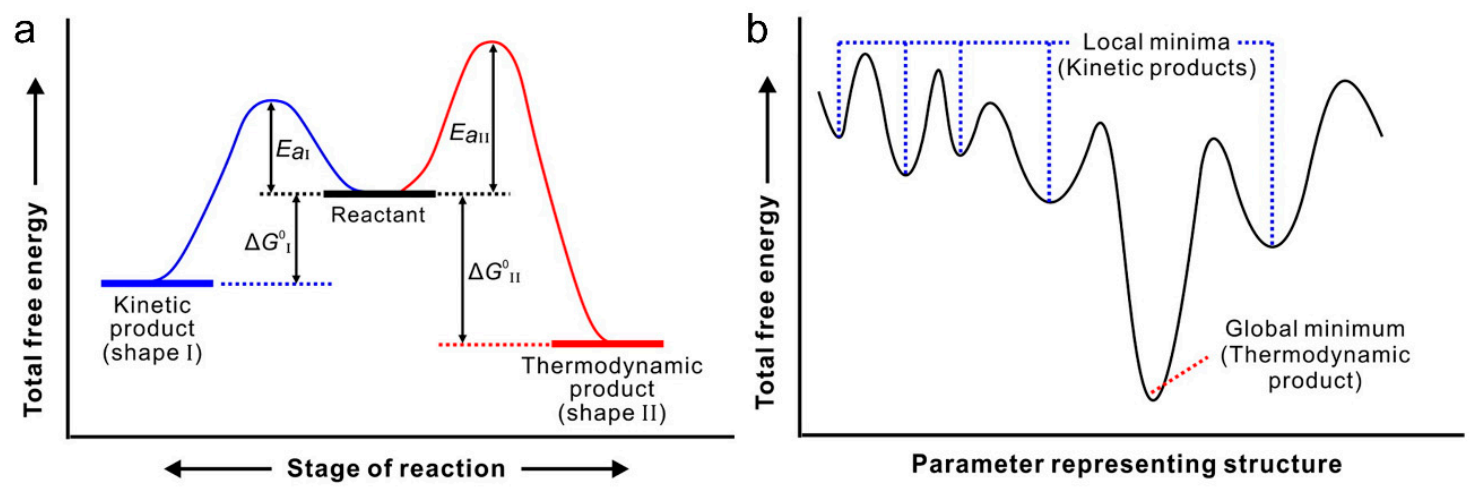

Figure 5. Schematic illustrations of thermodynamic and kinetic control for (a) two reactions, and (b) a series of reactions that involve product formation. Reproduced with permission from ref. [51]. Copyright 2015 American Chemical Society.

\subsection{Synthesis of Bimetallic Nanoparticles}

There are two general approaches to the synthesis of metal nanomaterials: top-down and bottom-up. The top-down approach is based on a solid-state physics strategy used to make nanostructures. This method begins with macroscopic-sized materials that are then made into structures having nanoscale sizes [53]. The top-down approach presents challenges in producing large quantities of uniformly shaped particles; however, to circumvent these issues, a bottom-up approach can be used. The bottom-up approach relies on synthetic pathways to prepare the nanomaterials of interest. In the bottom-up method, nanostructures are formed from a buildup of atoms found in solution or in the gas phase. Wet chemical syntheses, especially the reduction of metal salts, are an example of a bottom-up method that is reliable and frequently used [54]. The formation of metal nanoparticles by wet chemical methods can be divided into two main pathways: (1) the reduction of metal ions or (2) the thermal decomposition of metal precursors, as illustrated in Figure 6. Both initial pathways then lead to the formation of atoms, which will aggregate into clusters and grow to form the desired nanostructures [22]. 


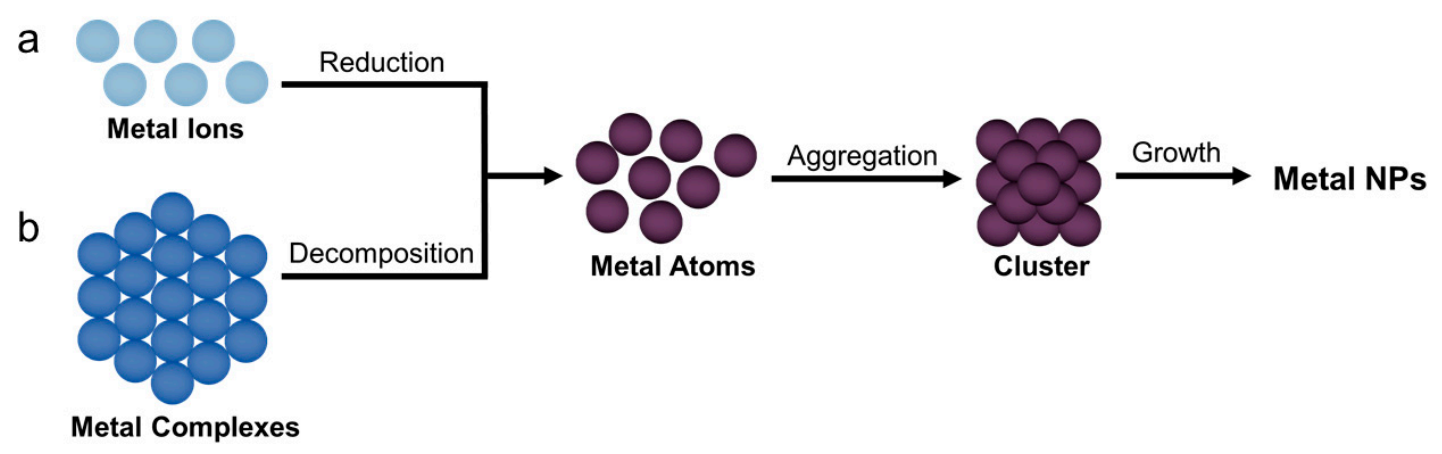

Figure 6. Reduction pathway (a) and decomposition pathway (b) for the formation of metal nanoparticles by chemical methods.

The preparation methods reported thus far can be divided into two categories: simultaneous and successive [55]. The simultaneous methods involve precursors of the two metals that are present in the same reaction system with or without protective agents; examples include chemical synthesis by co-reduction (citrate reduction [56], alcohol reduction [57], and polyol process [58]), sonochemical synthesis [59,60], thermal decomposition [61,62], microwave irradiation [63], and radiolytic synthesis [64]. The successive methods involve reducing metal ions over the surface of other nuclei followed by particle growth over time. Mild reducing agents used in these types of methods include formaldehyde [65], hydroxylamine hydrochloride [66], sodium citrate [67], and ascorbic acid [68]. As highlighted in the following sections and Table 1, certain methods are better suited and more commonly used for the synthesis of certain nanomaterials (i.e., most noble metal bimetallic nanoparticles use reduction methods, while most transition metal bimetallic nanoparticles are synthesized using thermal methods).

Table 1. Methods used for the synthesis of bimetallic nanoparticles.

\begin{tabular}{|c|c|c|c|}
\hline Material & Synthetic Method & Size & Reference \\
\hline \multirow{9}{*}{$\mathrm{AuAg}$} & $\begin{array}{l}\text { Polyol reduction } \\
\text { Galvanic replacement }\end{array}$ & $50 \mathrm{~nm}$ & [69] \\
\hline & $\begin{array}{c}\text { Co-reduction } \\
\text { Galvanic replacement }\end{array}$ & $10.2 \mathrm{~nm}$ & {$[70]$} \\
\hline & \multirow{2}{*}{ Chemical reduction } & $5 \mathrm{~nm}$ & [71] \\
\hline & & 32 and $45 \mathrm{~nm}$ & [72] \\
\hline & Radiolysis & $1.5-12 \mathrm{~nm}$ & {$[64]$} \\
\hline & Seed-mediated growth & $10-16 \mathrm{~nm}$ & [73] \\
\hline & Seed-mediated polyol process & $52 \mathrm{~nm}$ & [74] \\
\hline & In situ co-reduction method & $2.6 \mathrm{~nm}$ & {$[75]$} \\
\hline & $\begin{array}{l}\text { Successive ionic layer absorption and } \\
\text { reaction (SILAR) }\end{array}$ & $10-20 \mathrm{~nm}$ & [76] \\
\hline \multirow{2}{*}{$\mathrm{AuFe}$} & Chemical reduction & $15-30 \mathrm{~nm}$ & {$[61,77]$} \\
\hline & Laser ablation of a bulk alloy & $30-60 \mathrm{~nm}$ & {$[78,79]$} \\
\hline \multirow{4}{*}{$\mathrm{AuCo}$} & \multirow{3}{*}{ Chemical reduction } & $3-5 \mathrm{~nm}$ & {$[80]$} \\
\hline & & $14.2 \mathrm{~nm}$ & [26] \\
\hline & & $15-30 \mathrm{~nm}$ & [61] \\
\hline & Pulsed laser processes & $11 \mathrm{~nm}, 230 \mathrm{~nm}$ & {$[81,82]$} \\
\hline \multirow{2}{*}{$\mathrm{AuNi}$} & Chemical reduction & $15-30 \mathrm{~nm}$ & {$[61]$} \\
\hline & Electrodeposition & $100 \mathrm{~nm}$ and $200 \mathrm{~nm}$ & [83] \\
\hline
\end{tabular}


Table 1. Cont.

\begin{tabular}{|c|c|c|c|}
\hline Material & Synthetic Method & Size & Reference \\
\hline \multirow[b]{2}{*}{$\mathrm{AuCu}$} & Chemical reduction & $8.3 \mathrm{~nm}, 20-25 \mathrm{~nm}$ & {$[25,84]$} \\
\hline & $\begin{array}{l}\text { Chemical reduction using green synthesis } \\
\text { with Vitamin C }\end{array}$ & $5-50 \mathrm{~nm}$ & {$[68]$} \\
\hline \multirow{7}{*}{ AuPd } & $\begin{array}{l}\text { Hydrothermal conditions and } \\
\text { microwave irradiation }\end{array}$ & 40 to $65 \mathrm{~nm}, 150-200 \mathrm{~nm}$ & [85] \\
\hline & Chemical reduction & $1.6 \mathrm{~nm}$ & [58] \\
\hline & Sonochemical & $5-9 \mathrm{~nm}$ & {$[59,60,86,87]$} \\
\hline & Microwave-assisted polyol & $9 \mathrm{~nm}$ Au core, $3 \mathrm{~nm}$ Pd shell & {$[63]$} \\
\hline & \multirow{2}{*}{ Seed-mediated growth } & $5 \mathrm{~nm}$ & [50] \\
\hline & & $35-100 \mathrm{~nm}$ & [88] \\
\hline & Green synthesis & $7 \mathrm{~nm}$ & [89] \\
\hline \multirow{7}{*}{$\mathrm{AuPt}$} & Chemical reduction & $3 \mathrm{~nm}, 6 \mathrm{~nm}$ & {$[90,91]$} \\
\hline & Successive/reduction & $30 \mathrm{~nm}$ & [66] \\
\hline & Galvanic replacement & $\begin{array}{l}\text { The apex-apex length of the } \\
\text { concave nanocubes is } 12.81 \mathrm{~nm}\end{array}$ & [92] \\
\hline & Transmetalation reaction/replacement & $10-20 \mathrm{~nm}$ & [93] \\
\hline & Seed-mediated growth & $\begin{array}{c}\text { 3-8 } \mathrm{nm} \text { pearlike } \\
5-8 \mathrm{~nm} \text { peanutlike } \\
7-10 \mathrm{~nm} \text { cloverlike }\end{array}$ & [94] \\
\hline & Ultrasonochemical reduction & $39.5-101.6 \mathrm{~nm}$ & [95] \\
\hline & $\begin{array}{l}\text { Hydrothermal conditions and } \\
\text { microwave irradiation }\end{array}$ & $30 \mathrm{~nm}$ & [85] \\
\hline $\mathrm{PdCu}$ & $\begin{array}{c}\text { Chemical reduction using green synthesis } \\
\text { with Vitamin C }\end{array}$ & $5-50 \mathrm{~nm}$ & [68] \\
\hline $\mathrm{PtCu}$ & $\begin{array}{c}\text { Chemical reduction using green synthesis } \\
\text { with Vitamin C }\end{array}$ & $50-60 \mathrm{~nm}$ & [68] \\
\hline $\mathrm{PtRu}$ & Hydrothermal (thermal decomposition) & $2.5 \mathrm{~nm}$ & {$[62]$} \\
\hline \multirow{2}{*}{ PtPd } & Chemical reduction & $5-8 \mathrm{~nm}, 13 \mathrm{~nm}$ & {$[10,96]$} \\
\hline & Sonochemical & $2-3.6 \mathrm{~nm}$ & [97] \\
\hline $\mathrm{PdAg}$ & Galvanic replacement & Nanobox $63 \mathrm{~nm}$ in edge length & [98] \\
\hline \multirow{2}{*}{ PtAg } & Galvanic replacement & Nanobox $63 \mathrm{~nm}$ in edge length & [98] \\
\hline & Radiolytic synthesis & $3-20 \mathrm{~nm}$ & [99] \\
\hline $\mathrm{RhCu}$ & Soft-templating strategy & $74-135 \mathrm{~nm}$ & [100] \\
\hline $\mathrm{CuAg}$ & Sono and electrochemical synthesis & $10-80 \mathrm{~nm}$ & [101] \\
\hline \multirow{6}{*}{$\mathrm{FePt}$} & Chemical reduction & $3 \mathrm{~nm}, 12 \mathrm{~nm}$ & {$[34,102]$} \\
\hline & Pyrolysis (thermal decomposition) & $9 \mathrm{~nm}$ & [103] \\
\hline & Thermal decomposition & $12 \mathrm{~nm}$ & [104] \\
\hline & Polyol (chemical reduction) & $3-12 \mathrm{~nm}$ & [23,105-107] \\
\hline & Sonochemical & $3-5 \mathrm{~nm}$ & [108] \\
\hline & Hydrothermal & $9.4 \mathrm{~nm}$ & [109] \\
\hline \multirow{4}{*}{ FeCo } & Chemical reduction & $9 \mathrm{~nm}$ & [110] \\
\hline & $\begin{array}{l}\text { Physical vapor nanoparticle-deposition } \\
\text { technique }\end{array}$ & $3-100 \mathrm{~nm}$ & [39] \\
\hline & Thermal decomposition & $4,7 \mathrm{~nm}$ & [111] \\
\hline & Sputtering gas condensation technique & $12.8 \mathrm{~nm}$ & {$[112,113]$} \\
\hline
\end{tabular}


Table 1. Cont.

\begin{tabular}{cccc}
\hline Material & Synthetic Method & Size & Reference \\
\hline \multirow{2}{*}{ FeNi } & Chemical reduction & $12.2 \mathrm{~nm}$ & {$[114]$} \\
\cline { 2 - 4 } & Pyrolysis chemical reduction & $9 \mathrm{~nm}$ & {$[115]$} \\
\hline \multirow{2}{*}{$\mathrm{NiCo}$} & Microwave irradiation & $71 \mathrm{~nm}$ & {$[19]$} \\
\hline \multirow{2}{*}{$\mathrm{PtCo}$} & $\begin{array}{c}\text { Chemical reduction } \\
\text { Thermal decomposition }\end{array}$ & $3-18 \mathrm{~nm}$ & {$[116]$} \\
\cline { 2 - 4 } & Thermal decomposition & $6 \mathrm{~nm}$ & {$[40]$} \\
\hline $\mathrm{CoCu}$ & Chemical reduction & $5.3 \mathrm{~nm}$ & {$[117]$} \\
\hline $\mathrm{CuNi}$ & Sonochemical & $50 \mathrm{~nm}$ & {$[118]$} \\
\hline
\end{tabular}

\subsection{Simultaneous Methods}

\subsubsection{Co-Reduction}

Chemical co-reduction is a straightforward method that affords bimetallic nanoparticles from the reduction of two metal precursors to zerovalent atoms [120]. Major advantages of the co-reduction technique are its simplicity and versatility; several Ag@Au bimetallic core-shell nanoparticles having various shapes have been generated using this strategy. For example, Xia and co-workers prepared bimetallic AgAu nanocages using a polyol reduction reaction [69]. In these specific studies, an Au shell forms over a silver nanocube template to afford particles having a hollow interior, pinhole-containing surface, and crystalline walls. Silver nanocubes with $\mathrm{Pt}$ and $\mathrm{Pd}$ shells were also reported by Xia et al. [98]. These researchers demonstrated the formation of AgPt and AgPd nanoboxes through a galvanic replacement between $\mathrm{Ag}$ nanocubes and $\mathrm{Na}_{2} \mathrm{PtCl}_{4}$ and $\mathrm{Na}_{2} \mathrm{PdCl}_{4}$, respectively. Similarly, hollow bimetallic Ag@Pt core-shell nanoparticles with high Pt content were generated through the successive reductions of an aqueous solution of $\mathrm{AgNO}_{3}$ and $\mathrm{H}_{2} \mathrm{PtCl}_{6}$ with hydrazine by Tang et al. [21]. Similarly, concave Au@Pt nanocubes were prepared by Li et al. via galvanic replacement using Au@Ag nanocubes as templates, as shown in Figure 7 [92].

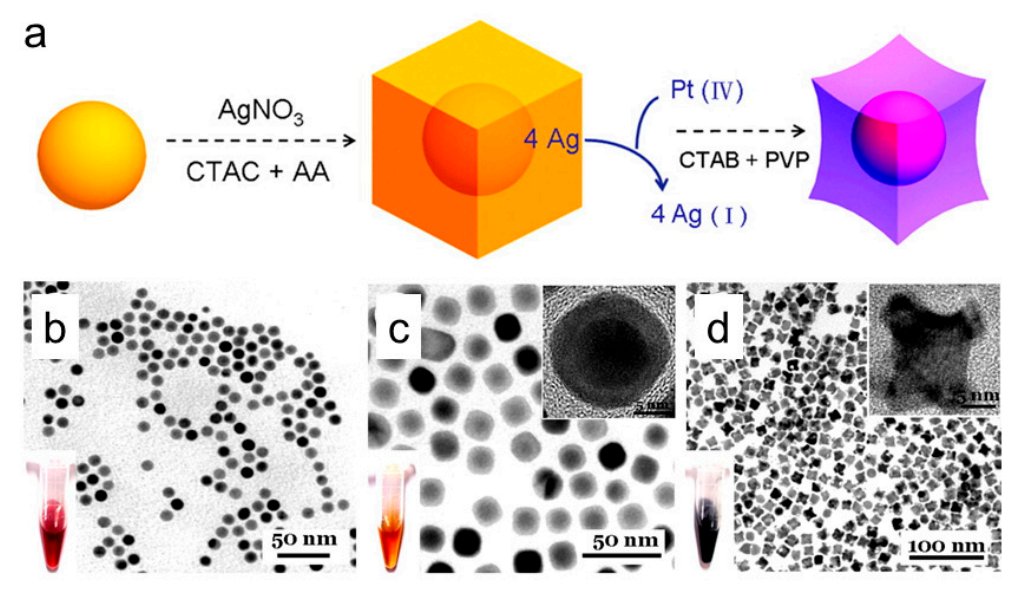

Figure 7. Schematic illustrations of (a) the formation of the concave Au@Pt nanocubes and TEM images and colloidal solutions (inset) of (b) Au NPs, (c) Au@Ag nanocubes, and (d) concave Au@Pt nanocubes. Reproduced with permission from ref. [92]. Copyright 2013 American Chemical Society.

Separately, there are several syntheses of nanoparticles that have been prepared in organic media $[22,70,96,121]$. The use of organic solvents is an attractive synthetic approach because it typically circumvents the agglomeration of nanoparticles that occurs in the presence of hydrophobic 
stabilizing ligands typically used in aqueous media [122]. For example, Yang et al. reported the synthesis of Ag@Au core-shell nanoparticles via a replacement reaction between hydrophobic Ag nanoparticles and $\left[\mathrm{AuCl}_{4}\right]^{-}$in toluene [70]. Furthermore, Sastry et al. prepared Ag@Pt core-shell particles through a replacement reaction between hydrophobic Au nanoparticles and hydrophilic $\mathrm{PtCl}_{6}{ }^{2-}$ ions in chloroform [93].

\subsubsection{Thermal Decomposition}

As highlighted in the preceding sections, noble metal nanoparticles can be prepared at room temperature through the reduction of the corresponding metal salts. However, for the synthesis of transition metal nanoparticles, higher temperatures are required due to the inability of the particles to crystallize at room temperature [123]. To employ this synthetic method successfully, the reaction must be conducted at or near the decomposition temperature of the metal precursors. The metal precursor that has lower decomposition temperature will form single-component metal nanoparticles, with the second metal precursor still in the solution. The second metal will be formed on the surface of the first metal nanoparticle when the temperature increases to the decomposition temperature of the second metal precursor.

Regarding specific examples, thermal-decomposition methods have been used for the synthesis of $\mathrm{CoPt}_{3}$ and $\mathrm{FePt}$ nanocrystals from cobalt and platinum precursors as well as iron and platinum precursors, respectively [116]. To control the size and shape of the nanoparticles, experimental conditions, such as, temperature, concentration of the stabilizing agents, and the ratio between the metal precursors are systematically varied. Additionally, Yang et al. demonstrated that FePt particles can be dispersed in organic solvents and water in addition to having good biocompatibility [105]. Furthermore, the thermal decomposition method has been used for the preparation of $\mathrm{FeCo}$, FeNi, $\mathrm{PtCo}$, and FeAu alloy nanoparticles [40,61,110,114,116]

\subsubsection{Radiolytic Synthesis}

The radiation-induced generation of metal clusters has proven to be a powerful method in the synthesis of bimetallic nanoparticles. In particular cases of the radiolytic reduction of metal ions in aqueous solution, the reducing radicals produced during the radiolysis of the solvents are used to reduce metal ions [124]. The radiolytic approach can offer certain advantages because of the fine control over the rate of generation of the growing species afforded by the control over the dose delivered to the sample. However, the radiolytic approach can suffer from difficulty in controlling the shape of the nanoparticles. It has been found that $\gamma$ irradiation of mixed solutions of the metal ions of two elements can yield perfectly ordered bimetallic clusters. The structure of the bimetallic nanoparticles depends on the irradiation dose rate because of the competition between the radiolytic reduction and the electron-transfer reaction from less noble metal atoms to other metal cations [124]. Alloy clusters are formed by radiolytic reduction at high dose rates because the reduction is sudden and faster than a possible inter-metal electron transfer. On the other hand, the radiation-induced reduction of mixed ions gives rise to bimetallic core/shell structures at low dose rates. For example, the production of AuAg bimetallic nanoparticles at different dose rates was studied by Treguer et al. [64]. These researchers found that the reduced silver atoms transfer electrons to gold ions at low dosage rates. When the $\mathrm{Au}^{\mathrm{III}}$ ions are totally reduced, the reduction of silver ions occurs in the second step at the surface of the gold clusters to afford silver-coated gold core/shell nanoparticles. In contrast, bimetallic alloyed AgAu clusters are formed at high dosage rates. Other bimetallic structures generated by $\gamma$ irradiation include Ag-Pt nanoparticles [99], Au-coated Ag nanoparticles [125], PdAu [126], and trimetallic PdAuAg particles [126].

Similarly, Boyer et al. reported the synthesis of subclustered $\mathrm{Au}$ and $\mathrm{Co}$ bimetallic nanoparticles consisting of nanoclusters fabricated by pulsed laser processes [81]. Femtosecond laser fragmentation offers the possibility to fabricate non-equilibrium nanostructures due to the rapid quenching that occurs during the synthesis. For this type of process, the nanoparticles are reheated and broken down 
into nanoclusters, which subsequently coalesce and aggregate with their neighbors. These metastable structures can also be transformed into more stable core-shell states using pulsed laser annealing [81]. In a separate study, Koshizaki proposed a method for preparing submicrometer-sized spheres by selectively pulse-heating colloidal nanoparticles in solution [127]. Recently, these researchers reported the generation of AuCo alloy particles by following the same laser ablation-in-liquid technique and using an unfocused laser to irradiate a solution mixture of colloidal gold and cobalt oxides [82]. Furthermore, this technique was found to be applicable for other nanoparticles with combinations of metals that are not thermodynamically stable under equilibrium, such as AuFe and AuNi [82]. For example, Amendola et al. were able to overcome the thermodynamic limitations of the room-temperature synthesis of AuFe nanoparticles by using their laser synthesis in solution (LASiS) method, illustrated in Figure 8 [78]. This environmentally-friendly, low-cost, laser-assisted preparation method shows promise as a synthetic method for the preparation of bioimaging agents [79].

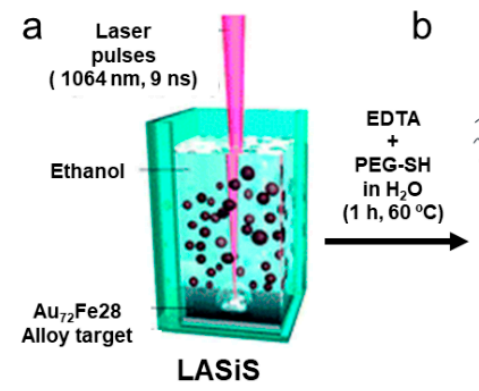

b
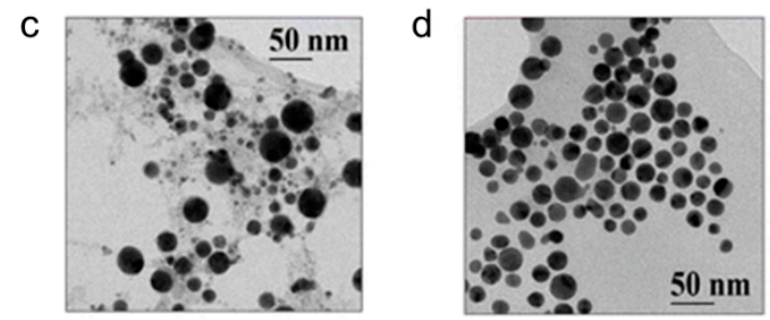

Figure 8. Two-step synthesis of PEG-AuFe NPs. (a) LASiS was used to synthesize AuFeNPs in ethanol from a bulk $\mathrm{Au}_{72} \mathrm{Fe}_{28}$ alloy. (b) EDTA and thiolated PEG was used to obtain water stable PEG-AuFe NPs. TEM images of (c) the nanoparticles obtained after LASiS and (d) after coating with the thiolated PEG. Reproduced with permission from ref. [78]. Copyright 2013 Royal Society of Chemistry.

\subsubsection{Sonochemical Synthesis}

The sonochemical synthesis of colloidal particles involves a rapid reaction rate and the ability to form unusually small metal particles. When solutions are exposed to strong ultrasound, micro bubbles in the solution implosively collapse and grow via acoustic fields where high-temperatures and high-pressures are produced, an effect known as acoustic cavitation [97]. The temperature generated through this method is sufficiently high to decompose molecules in the bubbles. In addition, sonication of a liquid medium also leads to the generation of oxidizing and reducing radicals [128]. These radicals play important roles in the synthesis of colloidal particles. Particularly for aqueous systems, primary radicals are generated within the bubbles through sonication, which consequently generate secondary radicals through the reaction with the bulk solution. A more detailed discussion of the sonochemical process to produce nanomaterials is found in the literature [129]

Sonochemical methods have been used for the synthesis of bimetallic nanoparticles. Mizukoshi et al. have applied the sonochemical method for the preparation of bimetallic AuPd nanoparticles with a narrow size distribution $[59,86]$. The particles were obtained by the simultaneous reductions of $\mathrm{Au}(\mathrm{III})$ and $\mathrm{Pd}(\mathrm{II})$ ions by ultrasonic treatment of an aqueous solution of sodium tetrachloroaurate(III) dihydrate and sodium tetrachloropalladate(II) in the presence of sodium dodecyl 
sulfate. Subsequent studies found that these bimetallic nanoparticles showed higher activity for the hydrogenation of 4-pentenoic acid than an analogous mixture of monometallic nanoparticles. In separate studies, Okitsu et al. prepared bimetallic AuPd nanoparticles using sonochemical reduction and a sol-gel processes at a relatively low temperature, less than $200{ }^{\circ} \mathrm{C}$ [87]. Separately, Jia et al. reported the sonochemical preparation of bimetallic $\mathrm{CoCu}$ nanoparticles in aqueous solution [130]. The synthesis method involved ultrasonic treatment of a hydrazine solution containing a mixture of copper chloride and cobalt chloride. The resultant bimetallic $\mathrm{CoCu}$ nanoparticles were shown to have an average diameter of $50 \mathrm{~nm}$ and a core-shell structure in which a copper core was surrounded by a thin cobalt shell. Wang et al. deposited FePt nanoparticles on silica microspheres modified with polyelectrolytes by a sonochemical process, using iron and platinum acetylacetonates as metal precursors [108]. Moreover, after the nucleation of FePt nanoparticles onto silica microspheres, they were coated with $\mathrm{ZnS}$. The $\mathrm{ZnS} / \mathrm{FePt} / \mathrm{SiO}_{2}$ nanospheres displayed both luminescent and magnetic properties after annealing, which renders them promising candidates for photocatalytic applications [108].

\subsection{Successive Methods}

\section{Seed-Mediated Growth}

The seed-mediated growth process begins by synthesizing a seed nanoparticle followed by subsequent growth, in solution, from metal precursors and reducing agents [131]. The seed-mediated method is typically used for the synthesis of well-defined bimetallic nanoparticles of core-shell and intermetallic structures due to the ability to control their size, shape, and composition [132]. In this type of synthetic process, reducing agents play an important role in controlling the size distribution of the nanoparticles. For example, strong reducing agents can create new nuclei in solution, which can lead to the formation of metal nanoparticles having two different sizes [133,134].

The most common combinations of metals used for the fabrication of bimetallic particles are gold and silver, palladium, or platinum due to their desired properties for a plethora of applications [135]. Srnova-Sloufova et al. used the seeded-growth method to prepare layered core-shell bimetallic Ag-Au nanocages in the 10-16 nm size range that were suitable for use in surface enhanced Raman spectroscopy (SERS) applications [73]. Park et al. synthesized Au@Ag core-shell nanoparticles having controllable shapes from spherical gold seeds. Various shapes synthesized on the gram scale include: cubes, cuboctahedrals, and octahedrons such as those shown in Figure 9 [74].
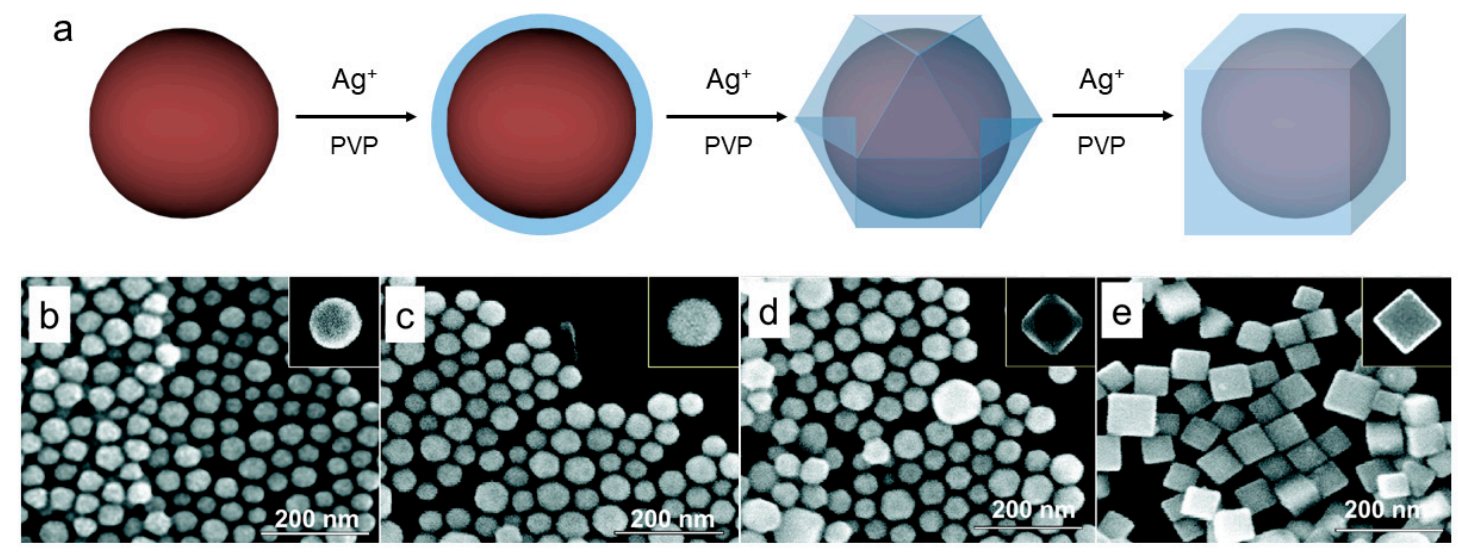

Figure 9. Schematic illustration of (a) Au@Ag core-shell nanopolyhedrons synthesized by the seed-mediated method and SEM images of (b) gold nanoseeds, (c) Au@Ag nanospheres, (d) Au@Ag cuboctahedrons, and (e) Au@Ag nanocubes. Reproduced with permission from ref. [74]. Copyright 2011 American Chemical Society. 
Bimetallic AuPd and AuPt nanoparticles have also been extensively studied in terms of their preparation, stabilization, and catalytic activity $[50,85,136,137]$. Hu et al. developed an Au-seeding method by which bimetallic core-shell nanoparticles can be readily synthesized with controllable sizes [88]. Following the method developed by Hu, core-shell Au@Pd nanoparticles with tunable sizes were prepared for use in practical SERS-based applications due to their high SERS activity, stability, and reversibility. In addition to synthesizing core-shell structures, a novel route for the synthesis of subclustered PtAu nanoparticles with controllable morphologies was developed by the overgrowth of $\mathrm{Au}$ onto Pt [94]. The size and shape of the nanoparticles were controlled by tuning the size of the $\mathrm{Pt}$ seeds or the solvent polarity to afford particles having clover-like, peanut-like, and pear-like shapes. Furthermore, certain morphologies proved to influence their catalytic performance, making this method a potential candidate for the rational synthesis of advanced materials for several types of catalytic applications.

\subsection{Other Synthetic Methods}

Most of the synthetic methods discussed in the previous sections occur in the liquid-phase. However, gas-phase synthetic methods have also been widely used to prepared both single-metal and multi-component nanoparticles and are reviewed in the literature [138]. Currently, green chemistry has received considerable attention, with new promising synthetic routes being proposed for the formation of nanoparticles that are environmentally friendly [139-141]. Some examples of the synthetic strategies being employed for the synthesis of bimetallic nanoparticles include the use of plant extracts [89,142], enzymes [143], and microorganisms [144] as reducing agents and capping agents. In addition to being non-hazardous, these reducing agents can be used at room temperature and atmospheric pressure, which not only saves energy, but also minimizes pollution that can accompany certain reaction pathways [44].

The use of bimetallic nanoparticles as catalysts has a long history but offers an ever-growing presence in the literature [145]. For example, Jiang et al. utilized a soft-templating technique to synthesize mesoporous bimetallic RhCu nanospheres [100]. In this example, the bimetallic nanoparticles were grown in the presence of a polymeric micelle, which was later removed to yield the mesoporous structure. Furthermore, bimetallic nanoparticles have also been directly fabricated on catalytic templates such as graphene, metal oxide structures, and biomolecules for use as electrodes in electrochemical reactions $[75,90,91,146]$.

Often, a combination of multiple synthetic strategies is employed for the fabrication of bimetallic nanoparticles. By combining more than one method, one can capitalize on the advantages each method offers. For example, ultrasound-assisted electrochemistry combines a sonochemical method with electrochemistry. This technique was utilized to synthesize core-shell nanoparticles by Mancier et al. for the generation of Cu@Ag nanoparticles [101]. Similarly, Li and co-workers combined galvanic replacement and diffusion through a protective porous silica shell to synthesize $\mathrm{SiO}_{2}$-coated hollow AgAu nanoparticles for use as stable plasmonic agents for NIR activation [1].

\subsection{Stabilization Strategies}

Due to their strong van der Waals interactions, metallic nanoparticles must be stabilized either electrostatically or sterically using coordinating (capping) agents that prevent the nanoparticles from aggregating. Electrostatic stabilization involves the columbic repulsion of the electrical double layer formed by ions adsorbed at the particle surface and between neighboring particles. When two particles are far apart or the distance between the particles is larger than the thickness of two electric double layers, the electrostatic repulsion between two particles is zero [147]. However, when two particles move closer, the two electric double layers overlap, and a repulsive force is developed. For example, the preparation of gold nanoparticles by Faraday's method uses the reduction of $\left[\mathrm{AuCl}_{4}\right]^{-}$by sodium citrate. The particles formed are surrounded by an electric double layer arising from adsorbed citrate and chloride ions and by the corresponding cations [148]. Similarly, Yin et al. prepared 
silver nanoparticles using the Tollens process without adding any external stabilizing agents. Under appropriate conditions, mixing of the reagents generates a stable dispersion of silver nanoparticles. The nanoparticles with dimension ranging from 20-30 $\mathrm{nm}$ were found to be stable for at least one year via electrostatic stabilization [149].

Steric stabilization, also called polymeric stabilization, is a method commonly used to stabilize metal nanoparticles. Polymer layers adsorbed on the surface of the nanoparticles also serve as a diffusion barrier to the growth of nuclei. The diffusion-limited growth gives rise to small but uniform initial nuclei, which lead to monodisperse nanoparticles [150]. Figure 10 shows a schematic representation of electrostatic stabilization and steric stabilization. The polymer layer can play three roles here: (1) it can prevent aggregation of the nanoparticles sterically, (2) it can enhance the formation of monodisperse particles via diffusion-limited growth, and (3) it can provide control of the morphology of the nanoparticles. For example, Murphy et al. synthesized Au and Ag nanorods with aspect ratios of 5:25 in the presence of cetyltrimethylammonium bromide (CTAB) [151]. Furthermore, Xia et al. demonstrated the large-scale synthesis of cubic silver nanoparticles with controllable shapes by using the polyol process [152]. The latter reaction involved the reduction of a precursor by ethylene glycol at elevated temperatures in the presence of poly(vinyl pyrrolidone) (PVP). In separate studies, Zheng et al. demonstrated a convenient and effective "thiol-frozen" approach to stabilize triangular silver nanoplates with bis(2-ethylhexyl) sulfosuccinate, which is also known as Aerosol OT or AOT [153].

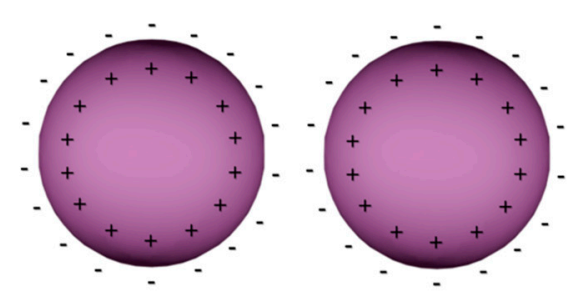

a

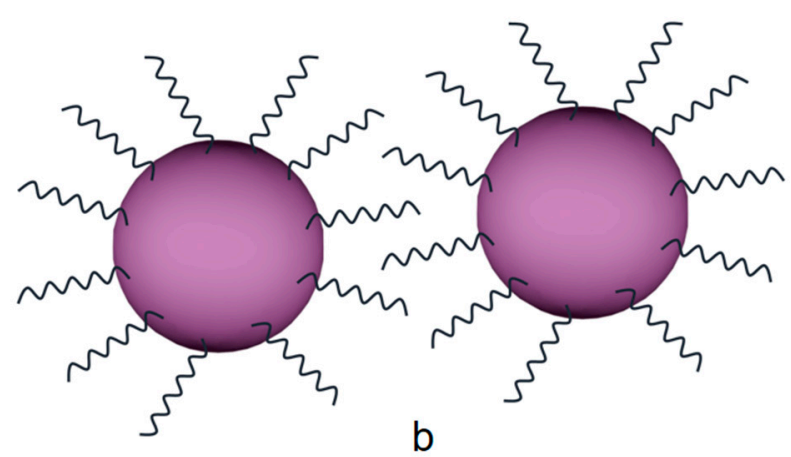

b

Figure 10. Schematic representations of (a) electrostatic stabilization and (b) steric stabilization in metallic nanoparticles.

\section{Biological Applications}

Metallic, bimetallic, and metal oxide nanoparticles have seen extensive use in biomedical applications [154]. The use of bimetallic nanoparticles for biological applications is focused on exploiting their optical or magnetic properties. For the following discussion, we have classified the selected biomedical applications based on their purpose: (1) diagnostic and/or (2) therapeutic. The applications categorized as diagnostic applications involve sensing and imaging. Applications categorized as therapeutic applications involve thermal treatments and drug-delivery systems.

\subsection{Diagnostic Applications}

The use of nanoparticles in diagnostic applications can be classified into two categories: sensing and imaging. Typically, plasmonic nanoparticles are employed as plasmonic biosensors for the detection of specific biomolecules. For example, metal nanoclusters of gold, silver, and copper have been well established as imaging agents in both in vitro and in vivo systems [155]. Magnetic nanoparticles as labels for biomolecule detection provide the advantage of low background signal for most biological samples. In addition to their unique magnetic separation properties used for sensing, magnetic nanoparticles can also act as contrast agents in imaging applications used for diagnosis. 


\subsubsection{Biosensors}

A biosensor is a device that provides qualitative and quantitative information about the chemical composition of the molecules in which the sensor is situated [156]. Plasmonic bimetallic nanoparticles have been used for biomolecular analyte detection based on their unique optical properties, including LSPR (vide supra). An additional factor affecting the wavelength at which the LSPR of plasmonic nanoparticles undergoes excitation is the refractive index of the medium surrounding the nanoparticles [157]. A medium with a relatively high refractive index, such as a buffer solution or biomolecules, will shift the LSPR to longer wavelengths [158]. Since most biomolecules have a higher refractive index than the buffer solution, the LSPR of the plasmonic nanoparticles conjugated with biomolecules will experience a red shift [159]. Another factor affecting the LSPR of nanoparticles is the degree of particle aggregation [160]. Specifically, certain biological molecules such as peptide nucleic acids (PNA), DNA aptamers, and protein antigens, can induce nanoparticle aggregation; a shift in the extinction peaks of the nanoparticles will then indicate the presence of the targeted molecules [161,162]. For example, Fan Zhang et al. used Au@Ag nanorods for the colorimetric sensing of the biological molecule alpha-fetoprotein, a biomarker for hepatocellular carcinoma in human serum [163].

Surface-enhanced Raman scattering (SERS) coupled with plasmonic materials has also been used for the detection of biological species due to the high selectivity and sensitivity of the technique; thorough reviews of the use of SERS in sensing applications can be found in the literature $[35,164,165]$. Recently, Kim et al. synthesized a label-free biosensing cellulose strip sensor with SERS-encoded bimetallic silver-gold core-shell nanoparticles (Ag@Au NPs) [76]. The biosensing material was characterized with Raman spectroscopy to evaluate the feasibility of detecting representative prohibited drugs with hazardous substances taken from patients including aniline, sodium azide, and malachite green. Recently, Bing-Liu et al. proposed an ultrasensitive biosensor based on gold-silver core-shell SERS nanotags and photonic crystal beads for the detection of proteins over a wide range of concentrations [166]. This biosensor showed a limit of detection of $672 \mathrm{fg} \mathrm{mL}^{-1}$ with a linear dynamic detection from $10 \mathrm{pg} \mathrm{mL}^{-1}$ to $10 \mu \mathrm{g} \mathrm{mL}^{-1}$, showing improved analytical performance for the Au@Ag NPs compared to that reported for simple Au NP-based nanotags.

Magnetic nanoparticles have also been used as biosensing materials [113,167]. Compared to their single-component oxides, bimetallic nanoparticles offer higher magnetic moments, which give rise to sensing materials with lower detection limits $[109,120]$. Magnetic bimetallic nanoparticles have been successfully applied as sensing agents in a variety of magnetic-based detection techniques. For example, sensing based on magnetic resistant biosensors utilizes the local magnetic dipole field produced by the change in the magnetoresistance signal of the magnetic nanoparticles. The higher magnetic moment of bimetallic nanoparticles offers stronger dipole fields and thus greater sensing potential [109]. Similarly, bimetallic nanoparticles have been used to improve the sensitivity of giant magnetoresistance (GMR) sensors used for biosensing applications through the modification of the particle size and shape $[112,113,168]$. By reducing the size of the particle or changing the shape from spherical to cubic, the binding density of the particle and the magnetic response both increase $[169,170]$. For example, $12 \mathrm{~nm}$ FeCo nanocubes have been used to quantify interleukin-6 (IL-6) and endoglin from unprocessed body fluids [112,113,168]. In addition, magnetic nanoparticles offer unique magnetic separation methods for multimodal detection, allowing for the capture and detection of target biomolecules at low concentrations [144,170,171]. For example, Xu et al. reported the capture of Gram-negative and Gram-positive bacteria by FePt nanoparticles with polyvalent ligands at an ultra-low concentration $(15 \mathrm{cfu} / \mathrm{mL})[170,171]$. The polyvalent ligand, vancomycin, provided a specific biofunctional receptor to capture the target bacteria. Moreover, $\mathrm{PtCo}$ bimetallic nanoparticles, displaying a unique combination of magnetism and oxidase-like catalytic activity, have been reported to enhance the colorimetric biosensing of MCF-7 cells [117]. The magnetic PtCo nanoparticles were conjugated with aptamers that can selectively capture cancer cells via their magnetic properties. Further, the magnetic nanoparticles show oxidase-like catalytic activity toward the oxidation of chromogenic 
substrates, which further enhances the quantitative detection of cancer cell lines through a colorimetric assay. These results highlight a detection method that can be observed with the naked eye without requiring $\mathrm{H}_{2} \mathrm{O}_{2}$ as an oxidant or illumination by light [117]. The fabricated bimetallic nanoparticles represent a facile, rapid, and highly selective detection method.

\subsubsection{Bioimaging}

The use of nanoparticles in bioimaging applications includes imaging at the molecular level and at markedly larger scales (e.g., organs). Plasmonic nanoparticles are typically limited to molecular imaging or can act as contrast agents in bioimaging applications. Gold nanoparticles of various shapes and sizes have been reported for bioimaging applications due to their low toxicity and biocompatibility $[172,173]$. Recently, Naha et al. developed gold-silver alloy nanoparticles (GSAN) to improve the efficiency of an imaging probe for breast cancer [71]. In this study, the GSAN enhanced the imaging contrast for dual-energy mammography (DEM) —an X-ray-based imaging technique used to screen for breast cancer.

Magnetic resonance imaging (MRI) is one of the most powerful imaging techniques in medical diagnosis. MRI measures the change in magnetization of protons under a magnetic field exposed to a radio frequency pulse [36]. The principle of the technique is based on the nuclear magnetic resonance effect where the local magnetic field produced by magnetic nanoparticles induces a change in the relaxation times of the surrounding protons. To investigate the enhancement of MRI signal, contrast agents act by accelerating the rate of relaxation of nearby water molecules, which increases the contrast between the tissue or organ of interest and the surrounding tissue [37]. Magnetic resonance (MR) contrast agents either accelerate the longitudinal relaxation $\left(\mathrm{T}_{1}\right)$ of water and produce bright "positive" contrast images or accelerate the transverse relaxation $\left(\mathrm{T}_{2}\right)$ and produce dark "negative" contrast images. For nanoparticle-based contrast agents, the relatively high magnetic moments of magnetic nanoparticles have been commonly used to shorten the $T_{2}$ of water protons in their vicinity, giving rise to an enhanced $\mathrm{T}_{2}$-weigthed MR images. The measurement and the effect of the contrast agents are typically measured as the $T_{2}$ relaxation time of water protons with a spin-echo pulse sequence and presented as the spin-spin relaxation rate $R_{2}$ where $R_{2}=1 / T_{2}$. The degree to which the contrast enhances the relaxation rate is denoted as the transverse relaxivity coefficient $\left(r_{2}\right)$, which is determined from the change of $R_{2}$ (spin-spin relaxation rate) as a function of the concentration of the magnetic material $[37,174]$. Particles that are large and have higher saturation magnetization values have been reported to provide higher relaxivity $\left(\mathrm{r}_{2}\right)$ [175]. Bimetallic nanoparticles with high magnetization, have thus attracted attention as contrast materials for MRI $[39,110,111]$.

Several types of bimetallic nanoparticles such as biophosphonated-functionalized FeNi nanoparticles, dextran-coated FeCo nanoalloys, PEGylated $\mathrm{Pt}_{3} \mathrm{Co}$ nanoparticles, and $\mathrm{CuNi}$ have been reported as $T_{2}$ contrast agents $[19,40,110,111,115]$. Maenosono et al. synthesized FePt nanoparticles capped with tetramethylammonium hydroxide (TMAOH) and found, by magnetic resonance relaxometry measurements, that TMAOH-capped FePt nanoparticles exhibit short $\mathrm{T}_{2}$ relaxation times, which renders them attractive for use as negative contrast agents in MRI [103]. Similarly, H. Yang et al. developed amphiphilic FePt nanoparticles capped with tetraethylene glycol and oleic acid [80]. The amphiphilic FePt nanoparticles can be efficiently endocytosed in living HeLa cells and offer good biocompatibility and high $\mathrm{T}_{2}$ relaxivities at $122 \mathrm{mM}^{-1} \mathrm{~s}^{-1}$ [105].

Dual modal imaging, using only one type of nanoparticle, can offer a more comprehensive diagnosis of cellular and in vivo imaging via CT/MRI [176]. For example, FePt nanoparticles have been conjugated with cysteamine and the antibody anti-Her2 and used as dual contrast agents for CT/MRI molecular imaging, as illustrated in Figure 11 [106]. The authors of the study used the polyol method to synthesize 3, 6, and $12 \mathrm{~nm}$ FePt nanoparticles and concluded that the $12 \mathrm{~nm} \mathrm{FePt}$ nanoparticles offered the highest amount of serum concentration as well as provided long-term circulation in both CT and MRI applications. 
a

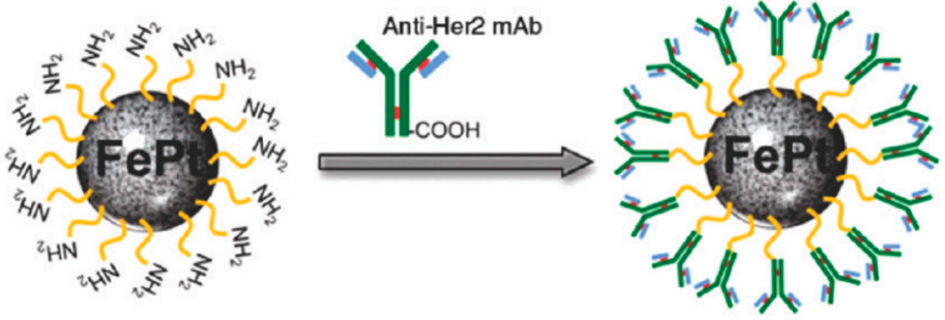

FePt nanoparticle as dual modality contrast agent for CT/MRI

b

In vitro test
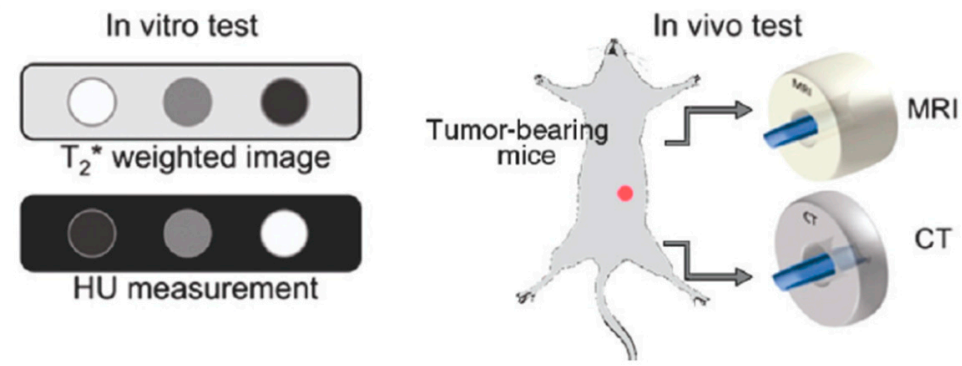

Figure 11. Schematic illustrations of (a) the surface functionalization of Anti-Her2 antibodies conjugated onto cysteamine capped FePt particles, and (b) in vitro and in vivo MRI and CT imaging using FePt nanoparticles as dual contrast agents. Reproduced with permission from reference [106]. Copyright 2010 American Chemical Society.

Surface coatings on bimetallic nanoparticles open new avenues for the creation of nanoparticles that offer higher stability, lower toxicity, and access toward a variety of functional groups [111,174]. Using chemical vapor deposition, Seo et al. synthesized FeCo nanoparticles having a graphitic shell [111]. The particles exhibited high $r_{1}$ and $r_{2}$ relaxivities and high optical absorbances in the NIR region. Preliminary in vivo experiments showed that these nanoparticles offer high-contrast in the MRI of the targeted tissue and NIR laser-triggered tumor destruction. Chen et al. showed that silica-coated FePt nanoparticles functionalized with cysteamine provided a six-fold increase in the relaxivity, $\mathrm{r}_{2}$, and lower cytotoxicity than the commercially offered colloidal suspension of superparamagnetic iron oxide particles known as Feridex [177]. Gao et al. designed and synthesized $3 \mathrm{~nm} \mathrm{FePt@Fe} \mathrm{O}_{3}$ yolk-shell nanoparticles through the Kirkendall effect [34]. The iron oxide surface of the nanoparticle allows for slow oxidation; thus, the yolk-shell nanoparticles were found to exhibit a strong MR contrast enhancement (effective relaxivity, $\left.\mathrm{r}_{2}{ }^{*}=3.462(\mu \mathrm{g} / \mathrm{mL})^{-1} \mathrm{~s}^{-1}\right)$. In addition, the low cytotoxicity of the $\mathrm{FePt} @ \mathrm{Fe}_{2} \mathrm{O}_{3}$ nanoparticles makes them a potential candidate for use in drug delivery. Separately, Chou et al., demonstrated the use of infrared-active FePt nanoparticles as a quadruple-contrast in multiscale molecular imaging in CT, MRI, photoacoustic imaging, and high-order multiphoton luminescence microscopy [102]. The FePt nanoparticles gave a higher photoacoustic response than gold nanorods and allowed for the visualization of in vivo targeting with four techniques at the same time, making them flexible and versatile imaging contrasts.

Magneto-plasmonic materials have also been employed for use as MRI, CT, and SERS imaging $[78,79,84]$. For example, Amendola et al. synthesized AuFe nanoalloys, a magneto-plasmonic material conjugated with thiolated PEG or dithiolated sulforhodamine [78,79]. The synthesized AuFe nanoparticles showed simultaneous MRI/CT imaging and in situ SERS imaging with amplification of Raman signals. Additionally, surface functionalization of the AuFe particles was found to render them biocompatible. Separate studies by Su et al. have led to the preparation of polyethyleneimine-coated $\mathrm{AuCu}$ nanoparticles with hollow structures as contrast enhancers in both $\mathrm{T}_{1}$ and $\mathrm{T}_{2}$ imaging, with $\mathrm{T}_{2}$ imaging done at low doses [84]. Further, the FePt-Au heterodimer metallic nanoparticles have been utilized in multimodal biological detection [178]. The Au segment offers high water solubility 
and biocompatibility after functionalization with dihydrolipoic acid through gold-sulfur bonds. The heterodimer nanoparticles were used in an avidin-biotin biochip assay and in MRI applications.

\subsection{Therapeutic Applications}

Nanoparticles offer a novel platform for the development of effective therapeutic treatments that offer specificity. The nanoparticles can be designed in such a way that allows the specific binding of a biological target to provoke a desired response. Both plasmonic and magnetic materials have proven to be useful in the thermal treatment of cancer. Likewise, drug-delivery systems that exploit the properties of these types of nanoparticles to release therapeutic agents have also received attention. In the following sections, we discuss treatments that are dependent on the optical or magnetic properties afforded by bimetallic nanoparticles for a variety of thermal treatments and drug-delivery applications. Table 2 provides a summary of the biological applications of bimetallic nanoparticles and the types of nanoparticles used in those applications.

\subsubsection{Thermal Treatments}

Thermal treatment, also called hyperthermia, is an emerging technique for therapeutic cancer treatment. This technique increases the temperature of the medium surrounding tumor cells. Research has established that tumor cells are sensitive and can be destroyed at temperatures above $42{ }^{\circ} \mathrm{C}$ [179]. The heat generated in hyperthermia treatments can originate from ultrasonication, radiofrequency, or other types of irradiation [180]. These methods, however, can sometimes cause severe damage to surrounding healthy cells [10,42]. In efforts to develop a more targeted approach, researchers have described the use of metallic nanoparticles that can locally heat the tumor cells without damaging the surrounding healthy tissue $[181,182]$. To provide specificity, the nanoparticles can be conjugated with antibodies that preferentially bind to tumor cells, and upon NIR irradiation, the absorbed photolytic energy causes the nanoparticles to warm, leading to the destruction of the tumor tissues $[183,184]$.

Gold nanoparticles have been reported for use in photothermal therapies based on the optical properties and biocompatibility. As previously mentioned, bimetallic nanomaterials, especially gold-based bimetallic nanoparticles, can be designed for activation at visible and NIR wavelengths, making them suitable for use in photothermal cancer therapy. For example, bimetallic AgAu nanocages have been evaluated as potential materials for photothermal therapy $[69,185]$. The surface plasmon resonance of these types of nanocages can be tuned to the NIR region ( 800 to $2500 \mathrm{~nm}$ ), making them compatible with the wavelength of laser irradiation used in many photothermal therapies [38]. Under laser irradiation, gold nanocages generate extremely high local temperatures that can provide a destructive effect on cancer cells without destroying the particles themselves [167]. Recent simulation studies have explored the process by which thermal damage of the lipid bilayer occurs by this process and the subsequent increased permeability of the membrane [186]. Moreover, due to their strong and tunable surface plasmon resonance, gold nanocages can also be used as a potential contrast enhancement agent for optical coherence tomography (OCT) and spectroscopic optical coherence tomography (SOCT) for the imaging of biological tissues for early cancer detection [72]. Furthermore, in addition to plasmonic materials, magnetic particles have also been employed for photothermal therapy using magnetic FePt nanoparticles [104]. Chen et al. demonstrated the capability of FePt nanoparticles to heat to $100{ }^{\circ} \mathrm{C}$ in picoseconds via femtosecond-laser irradiation. Under the localized energy irradiation, FePt nanoparticles can trigger photothermolysis and then effectively kill cancerous cells [104]. 
Table 2. Bimetallic nanoparticles in biological applications.

\begin{tabular}{|c|c|c|c|}
\hline Application & Principle & Materials & Reference \\
\hline \multirow{8}{*}{ Sensing } & LSPR shift & $\mathrm{AuAg}$ & [163] \\
\hline & \multirow{2}{*}{ Surface-enhanced Raman scattering (SERS) } & $\mathrm{AuAg}$ & [76] \\
\hline & & $\mathrm{AuAg}$ & [166] \\
\hline & GMR sensor; competition assay & FeCo & {$[112,113,187]$} \\
\hline & Magnetic capture & $\mathrm{FePt}$ & {$[171]$} \\
\hline & Magnetically-enhanced colorimetric biosensing & PtCo & [117] \\
\hline & QCM with magnetically controlled permeability & $\mathrm{AuCo}$ & [80] \\
\hline & Electrochemical biosensor & $\mathrm{PtPd}$ & {$[96]$} \\
\hline \multirow{15}{*}{ Imaging } & $\begin{array}{l}\text { An imaging probe screening with dual energy } \\
\text { mammography or computed tomography }\end{array}$ & AuAg & [71] \\
\hline & The optical absorption cross sections & $\mathrm{AuAg}$ & [72] \\
\hline & MRI contrast agent (no imaging) & $\mathrm{FePt}$ & [103] \\
\hline & \multirow{3}{*}{ MRI in vitro } & $\mathrm{FePt}$ & [105] \\
\hline & & FeNi & [115] \\
\hline & & PtCo & {$[40]$} \\
\hline & \multirow{3}{*}{ MRI in vivo } & $\mathrm{AuCu}$ & [84] \\
\hline & & FeCo & [110] \\
\hline & & $\mathrm{FePt}$ & {$[177]$} \\
\hline & $\begin{array}{l}\text { Dual modal CT/MRI molecular imaging } \\
\text { in vitro and in vivo }\end{array}$ & $\mathrm{FePt}$ & [132] \\
\hline & MRI and near-infrared agents & $\mathrm{FeCo}$ & [111] \\
\hline & Multimodal imaging & & \\
\hline & $\begin{array}{ll}- & \text { Computed tomography (CT), } \\
- & \text { Magnetic resonance imaging (MRI), } \\
- & \text { Photoacoustic (PA) imaging, } \\
- & \text { High-order multiphoton luminescence } \\
& (\text { HOMPL) microscopy }\end{array}$ & $\mathrm{FePt}$ & [102] \\
\hline & in vivo Multimodal SERS-MRI-CT imaging & $\mathrm{AuFe}$ & {$[79]$} \\
\hline & $\begin{array}{l}\text { in vivo NIR thermal imaging and } \\
\text { photoacoustic imaging }\end{array}$ & $\mathrm{AuPt}$ & [95] \\
\hline \multirow{4}{*}{$\begin{array}{l}\text { Thermal } \\
\text { treatment }\end{array}$} & in vitro hyperthermia & $\mathrm{FePt}$ & [109] \\
\hline & Photothermal & $\mathrm{FePt}$ & [104] \\
\hline & Hyperthermia & $\mathrm{CuNi}$ & {$[119,188]$} \\
\hline & Tumor chemo-photothermal therapy & $\mathrm{AuPt}$ & [95] \\
\hline \multirow{4}{*}{ Drug delivery } & $\begin{array}{l}\text { Drug carrier by pore structure and release by } \\
\text { photothermal conversion }\end{array}$ & $\mathrm{FePt}$ & [109] \\
\hline & Gene delivery by functionalized surface & $\mathrm{AuNi}$ & [83] \\
\hline & Drug delivery by pore structure & $\mathrm{AuPt}$ & [95] \\
\hline & Photothermally enhanced photodynamic therapy & PdAg & {$[118,189]$} \\
\hline
\end{tabular}

In addition to photothermal treatments, another class of hyperthermia treatment is magnetic hyperthermia - a therapy that depends on magnetic nanomaterials that can be selectively positioned near target cells and generate localized heat when exposed to an alternating external magnetic field. 
In the presence of an alternating magnetic field, magnetic nanoparticles continuously generate energy as heat due to Nèel and Brownian relaxation [37,190,191]. The heating efficiency of a magnetic nanoparticle is determined from the specific loss power (SLP), which is a measurement of the change in temperature per unit volume or mass of the nanoparticles $[37,98]$. The SLP values are proportional to the $\mathrm{M}_{\mathrm{S}}$ value but inversely proportional to the size distribution of the nanoparticles [37]. The optimized magnetic anisotropy and size also can enhance the SLP. Therefore, a material with a high SLP value can bring enhanced efficacy with a lower number of nanoparticles. Temperature control in this type of application can be achieved with an intense alternating magnetic field and a particle with a low Curie temperature $\left(T_{c}\right)$, typically in the range of 42 to $46{ }^{\circ} \mathrm{C}$ [191-193]. Magnetic nanoparticles with a low Curie temperature (the temperature at which magnetic materials transition between ferromagnetic and paramagnetic properties) can be effectively heated to a temperature below their $T_{c}$ to prevent damage to neighboring healthy tissues since at these temperatures, there is a decrease in magnetic coupling interactions in the paramagnetic regime. Nanoparticles suitable for magnetic hyperthermia must be biocompatible as well as monodisperse with simultaneously high and self-regulated heating capability, with a desired Curie temperature less than $60^{\circ} \mathrm{C}$ [194].

Several bimetallic nanoparticles have been reported as successful magnetic hyperthermia mediators, including $\mathrm{CuNi}$ and FeNi $[114,119,188]$. For example, mechanically milled CuNi nanoparticles can be obtained at a size of $10 \mathrm{~nm}$ with a $\mathrm{T}_{\mathrm{C}}$ of $45^{\circ} \mathrm{C}$. These particles show a significant self-heating effect over $40^{\circ} \mathrm{C}$, as determined by analysis using a thermogravimetric analyzer-simultaneous differential thermal analysis (TGA-SDTA) technique [119]. Additionally, $\gamma$-FeNi nanoparticles with a tunable Curie temperature have also been reported by McHenry et al. for use in self-regulated hyperthermia. In their studies, the authors found that the ratio of Fe and $\mathrm{Ni}$ led to significant variations in the $\mathrm{M}_{\mathrm{s}}$ and $\mathrm{T}_{\mathrm{c}}$, where higher amounts of Fe gave higher values. Moreover, FeNi nanoparticles with extra Mn precursors added can further reduce the $T_{c}$ from $82{ }^{\circ} \mathrm{C}$ to $78^{\circ} \mathrm{C}[114]$.

\subsubsection{Drug Delivery}

Delivering therapeutic compounds to target sites has been a major obstacle in many applications. A solution to the problem is cell-specific targeting treatments, which can be achieved by attaching drugs onto individually designed carriers [195]. Nanoparticles have been used as carriers in targeted drug delivery to deliver therapeutic agents at the disease site, improve the uptake of poorly soluble drugs, and improve drug bioavailability [196]. Furthermore, the small sizes and unique physicochemical and biological properties render nanoparticles to be promising candidates as drug carriers [195].

Gold-based bimetallic nanoparticles are particularly promising candidates as drug carriers due to their small size, biocompatibility, and facile surface modification [197]. For example, Liu et al. altered the plasmonic properties of porous-silica-coated AuAg alloy nanoparticles with built-in hotspots where the electromagnetic field was sufficiently strong to amplify the Raman scattering of target molecules [198]. These types of materials are suitable for drug delivery and photothermal therapeutics owing to their size in the range of nanometers, porous structure of both the core and shell, and the unique optical activity in the NIR region [198]. Other examples of modified gold-based nanoparticles for drug delivery include the cationic BSA embedded AuAg bimetallic nanocluster system developed by Dutta. In their study, the authors used BSA to synthesize the unique architecture to serve as a carrier for the pDNA encoding of the enzyme E. coli cytosine deaminase uracil phosphoribosyltransferase (CD-UPRT) [155]. The nanoclusters were then converted into composite nanoparticles and bound to the negatively charged pDNA. Successful uptake of the composite nanoparticles was achieved by the cancer cells. To track the delivery of pDNA into the cells, the luminescence of the bimetallic nanoclusters was used. Separately, AuNi nanorods have been designed as selectively functionalized carriers for gene delivery [83]. The nanorods were double functionalized with transferrin on the $\mathrm{Au}$ segment and DNA plasmids on the Ni segment. The dual-functionalized nanorods demonstrated their potential use as carriers for gene-delivery into human cells for targeted protein expression [83]. 
In addition to exploring the drug-delivery efficacy, recent nanoparticle-based research has also focused on developing additional capabilities that are beneficial to the patients receiving the treatments, such as reducing the systemic toxicity. Yang et al., for example, synthesized multifunctional Au@Pt nanoparticles that allow for the loading of the anticancer drug, doxorubicin (DOX) [95]. The DOX-loaded nanoparticles serve as a chemo-photothermal combination therapy platform with oxidative stress reduction (Figure 12). In addition to gold-based bimetallic nanoparticles, Shi et al. demonstrated that mesoporous silica-coated Pd@Ag nanoparticles $\left(\mathrm{Pd} @ \mathrm{Ag} @ \mathrm{mSiO}_{2}\right)$ can be used as a nanoplatform for photodynamic therapy (PDT) in drug delivery [190]. These nanocomposites were utilized as nanocarriers for the photosensitizer Ce6 in photothermally enhanced photodynamic therapy.

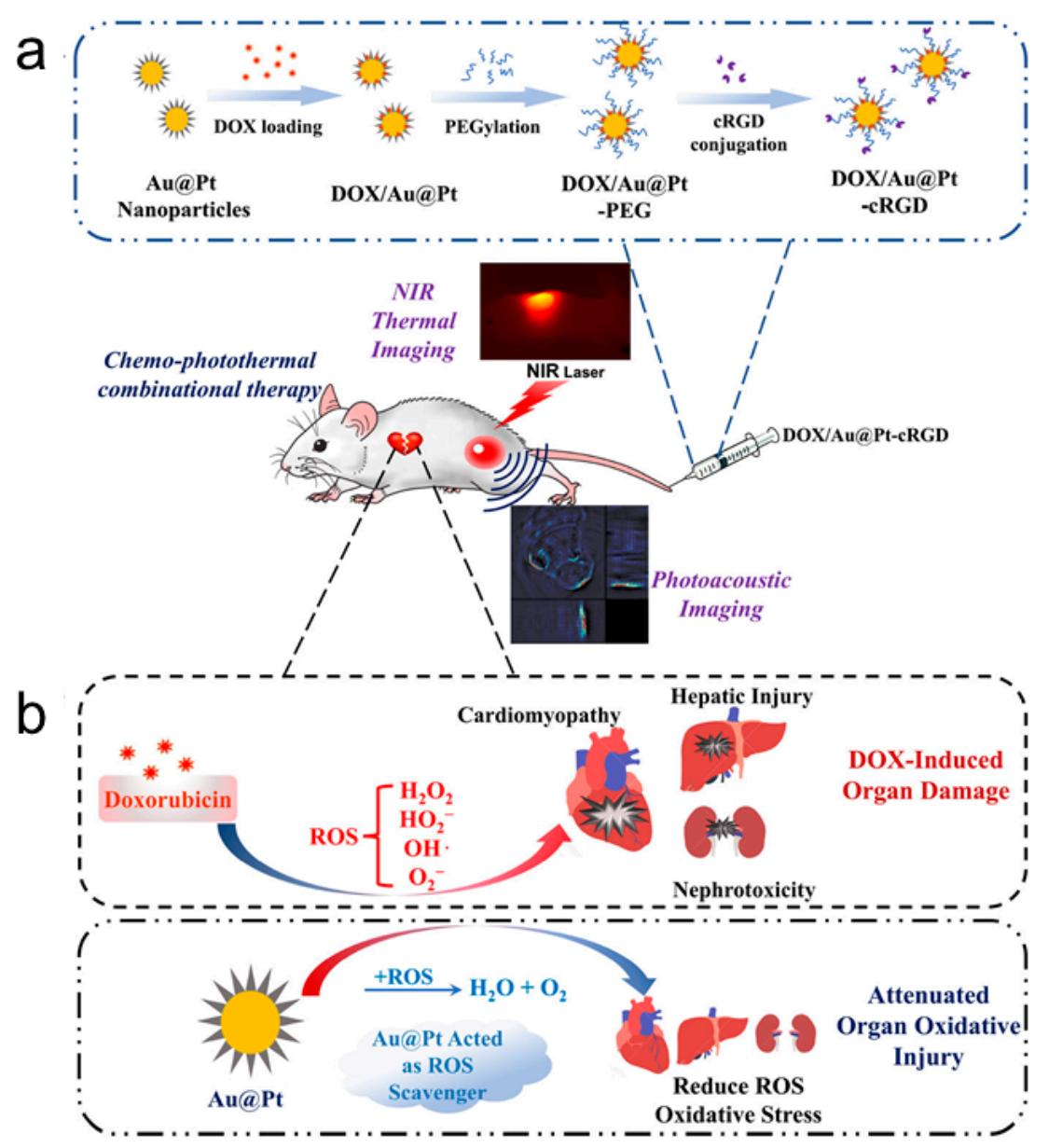

Figure 12. Schematic illustrations of (a) the synthesis of DOX/Au@Pt-cRGD, and (b) ROS scavenging by catalyzing the platinum shell while attenuating DOX-induced organ oxidative injury. Reproduced with permission from ref. [95]. Copyright 2017 American Chemical Society.

Magnetically guided capsules using an external magnetic field have also gained attention as a potential method for controlled drug delivery. The use of $\mathrm{pH}$ - and temperature-sensitive polymeric materials as coatings on magnetic nanoparticles have proven to be good candidates for controlled drug release $[19,80,107,176]$. Lu et al. optimized polyelectrolyte embedded Co@Au nanoparticles for magnetically controlled permeability [80]. The permeability of the nanoparticles was achieved by applying an appropriate frequency to cause the oscillating magnetic field to "twist and shake" the nanoparticles. Another example of a potential magnetically guided drug-delivery system is the polycation hybrid FePt nanoparticle-coated capsules developed by Fuchigami et al. [107].

Sahu et al. synthesized PEGylated $\mathrm{FePt}_{-} \mathrm{Fe}_{3} \mathrm{O}_{4}$ nanoassemblies for the $\mathrm{pH}$-sensitive release of DOX in a cell-mimicking environment [109]. The authors found higher release of DOX in acidic 
environments $(\mathrm{pH}$ 4.3) than at physiological $\mathrm{pH}(\mathrm{pH}$ 7.4) due to the protonation of DOX under acidic media. In addition, due to the magnetic nature of the nanoparticles, the DOX release was enhanced under an alternating magnetic field, which was used to increase the Brownian motion of the nanoparticles. Another example of a pH-responsive bimetallic nanogel was reported by Wu et al. [199]. The nanogel was composed of core-shell Ni@Ag bimetallic nanoparticles coated with poly(ethylene glycol-co-meth-acrylic acid) [p(EG-MAA)]. Due to the nature of the composite, the material could be magnetically manipulated, and drug release was regulated via the $\mathrm{pH}$-sensitive properties of the polymeric material.

\section{Summary and Perspectives}

As described in this review, there are various kinds of structures bimetallic nanoparticles can adopt depending on the atomic ordering of the two metals. The structures can be broadly classified as mixed structures and segregated structures. Synthetic methods can be divided into simultaneous (e.g., co-reduction, sonochemical synthesis, thermal decomposition, microwave irradiation, and radiolytic synthesis) and successive methods (e.g., seed-mediated growth). Bimetallic nanoparticles prepared via these methods offer advances in a variety of biological applications that range from diagnostics (e.g., sensing and imaging) to therapeutics (e.g., tumor ablation and drug delivery). Bimetallic nanoparticles with plasmonic properties, such as $\mathrm{Au} / \mathrm{Ag} / \mathrm{Cu}$ composites, are typically employed as plasmonic biosensors due to the sensitivity of their LSPR to the surrounding medium. Most imaging techniques, such as magnetic resonance imaging (MRI), computed tomography (CT), and dual modal imaging, require the use of a contrast agent. Due to the magnetic nature of Fe, $\mathrm{Co}$, or $\mathrm{Ni}$ bimetallic nanoparticles, these types of materials serve as good contrast agents in imaging techniques. Additionally, magneto-plasmonic materials, such as Au-Fe nanoparticles, have useful in multimodal biological detection and imaging diagnostic techniques due to their combined optical and magnetic properties.

Both plasmonic and magnetic bimetallic nanoparticles have been used in therapeutic applications, including thermal treatments (hyperthermia) and drug delivery. By taking advantage of the tunable LSPR of plasmonic nanoparticles (e.g., Au-based bimetallics) or the relaxation of magnetic nanoparticles (e.g., Fe-based bimetallics), specific cells can be targeted for treatment without damaging the surrounding tissues. Additionally, Au-based nanoparticles have been proven to be excellent candidates for drug delivery due to their biocompatibility. Moreover, Fe-based materials coupled with $\mathrm{pH}$ - or temperature-sensitive coatings can be magnetically controlled for targeted drug release. The optical and magnetic properties inherent in bimetallic nanoparticles render these types of materials promising candidates for improving the efficiency of diagnostic and therapeutic applications. As described in this review, various kinds of bimetallic nanoparticles have been used in diagnostic applications such as imaging and sensing. However, there are comparatively fewer examples in the literature for therapeutic applications, especially for use in the treatment of cancer. This paucity coupled with emerging synthetic strategies in the synthesis of bimetallic nanoparticles and technological advances will hopefully fill the void. Further, the use of multi-component nanoparticles comprised of three or more metals have also emerged as materials that can enhance the optical and magnetic properties discussed herein. Undoubtedly, we will continue to see creative advances in the synthesis and applications of these unique dual-component and multi-component nanomaterials.

Author Contributions: P.S., Y.-T.C., V.V., M.D.M., and T.R.L. discussed, commented, and wrote the manuscript.

Funding: We thank the Air Force Office of Scientific Research (AFOSR FA9550-18-1-0094), the Robert A. Welch Foundation (E-1320), and the Texas Center for Superconductivity for generously supporting this research.

Conflicts of Interest: The authors declare no competing financial interest. 


\section{References}

1. Li, C.-H.; Li, M.-C.; Liu, S.-P.; Jamison, A.C.; Lee, D.; Lee, T.R.; Lee, T.-C. Plasmonically enhanced photocatalytic hydrogen production from water: The critical role of tunable surface Plasmon resonance from gold-silver nanoshells. ACS Appl. Mater. Interfaces 2016, 8, 9152-9161. [CrossRef] [PubMed]

2. Hien Pham, T.T.; Cao, C.; Sim, S.J. Application of citrate-stabilized gold-coated ferric oxide composite nanoparticles for biological separations. J. Magn. Magn. Mater. 2008, 320, 2049-2055. [CrossRef]

3. Li, J.J.; Peng, X. Photocatalytic activity of gold nanocrystals and its role in determining the stability of surface thiol monolayers. J. Nanosci. Nanotechnol. 2004, 4, 565-568. [CrossRef] [PubMed]

4. Tessier, P.M.; Velev, O.D.; Kalambur, A.T.; Rabolt, J.F.; Lenhoff, A.M.; Kaler, E.W. Assembly of gold nanostructured films templated by colloidal crystals and use in surface-enhanced Raman spectroscopy. J. Am. Chem. Soc. 2000, 122, 9554-9555. [CrossRef]

5. Kim, S.-W.; Kim, M.; Lee, W.Y.; Hyeon, T. Fabrication of hollow palladium spheres and their successful application as the recyclable heterogeneous catalyst for Suzuki coupling reactions. J. Am. Chem. Soc. 2002, 124, 7642-7643. [CrossRef] [PubMed]

6. Nicewarner-Peña, S.R.; Freeman, R.G.; Reiss, B.D.; He, L.; Peña, D.J.; Walton, I.D.; Cromer, R.; Keating, C.D.; Natan, M.J. Submicrometer metallic barcodes. Science 2001, 294, 137-141. [CrossRef] [PubMed]

7. Chen, J.; Saeki, F.; Wiley, B.J.; Cang, H.; Cobb, M.J.; Li, Z.-Y.; Au, L.; Zhang, H.; Kimmey, M.B.; Li, X. Gold Nanocages: Bioconjugation and their potential use as optical imaging contrast agents. Nano Lett. 2005, 5, 473-477. [CrossRef] [PubMed]

8. Song, L.; Mao, K.; Zhou, X.; Hu, J. A novel biosensor based on Au@Ag core-shell nanoparticles for SERS Detection of Arsenic (III). Talanta 2016, 146, 285-290. [CrossRef] [PubMed]

9. Varghese, R.; Almalki, M.A.; Ilavenil, S.; Rebecca, J.; Choi, K.C. Silver nanopaticles synthesized using the seed extract of Trigonella Foenum-Graecum L. and their antimicrobial mechanism and anticancer properties. Saudi J. Biol. Sci. 2017, in press. [CrossRef]

10. Li, X.; Liu, H.; Liu, S.; Zhang, J.; Chen, W.; Huang, C.; Mao, L. Effect of Pt-Pd hybrid nano-particle on CdS's Activity for water splitting under visible light. Int. J. Hydrog. Energy 2016, 41, 23015-23021. [CrossRef]

11. Logunov, S.L.; Ahmadi, T.S.; El-Sayed, M.A.; Khoury, J.T.; Whetten, R.L. Electron dynamics of passivated gold nanocrystals probed by subpicosecond transient absorption spectroscopy. J. Phys. Chem. B 1997, 101, 3713-3719. [CrossRef]

12. Burda, C.; Chen, X.; Narayanan, R.; El-Sayed, M.A. Chemistry and properties of nanocrystals of different shapes. Chem. Rev. 2005, 105, 1025-1102. [CrossRef] [PubMed]

13. Bratescu, M.A.; Cho, S.-P.; Takai, O.; Saito, N. Size-controlled gold nanoparticles synthesized in solution Plasma. J. Phys. Chem. C 2011, 115, 24569-24576. [CrossRef]

14. Naskar, S.; Freytag, A.; Deutsch, J.; Wendt, N.; Behrens, P.; Köckritz, A.; Bigall, N.C. Porous aerogels from shape-controlled metal nanoparticles directly from nonpolar colloidal solution. Chem. Mater. 2017, 29, 9208-9217. [CrossRef]

15. Personick, M.L.; Langille, M.R.; Zhang, J.; Mirkin, C.A. Shape control of gold nanoparticles by silver underpotential deposition. Nano Lett. 2011, 11, 3394-3398. [CrossRef] [PubMed]

16. Wang, F.; Tang, R.; Yu, H.; Gibbons, P.C.; Buhro, W.E. Size- and shape-controlled synthesis of bismuth nanoparticles. Chem. Mater. 2008, 20, 3656-3662. [CrossRef]

17. Murphy, C.J.; Jana, N.R. Controlling the aspect ratio of inorganic nanorods and nanowires. Adv. Mater. 2002, 14, 80-82. [CrossRef]

18. Wiley, B.J.; Chen, Y.; Mclellan, J.M.; Xiong, Y.; Li, Z.-Y.; Ginger, D.; Xia, Y. Synthesis and optical properties of silver nanobars and nanorice. Nano Lett. 2007, 7, 1032-1036. [CrossRef] [PubMed]

19. Yamauchi, T.; Tsukahara, Y.; Yamada, K.; Sakata, T.; Wada, Y. Nucleation and growth of magnetic Ni-Co (Core-shell) nanoparticles in a one-pot reaction under microwave irradiation. Chem. Mater. 2011, $23,75-84$. [CrossRef]

20. Khodashenas, B.; Ghorbani, H.R. Synthesis of silver nanoparticles with different shapes. Arab. J. Chem. 2015, in press. [CrossRef]

21. Gao, J.; Ren, X.; Chen, D.; Tang, F.; Ren, J. Bimetallic Ag-Pt hollow nanoparticles: Synthesis and tunable surface Plasmon resonance. Scr. Mater. 2007, 57, 687-690. [CrossRef] 
22. Toshima, N.; Yonezawa, T. Bimetallic nanoparticles-novel materials for chemical and physical applications. New J. Chem. 1998, 22, 1179-1201. [CrossRef]

23. Sun, S.; Murray, C.B.; Weller, D.; Folks, L.; Moser, A. Monodisperse FePt nanoparticles and ferromagnetic FePt nanocrystal superlattices. Science 2000, 287, 1989-1992. [CrossRef] [PubMed]

24. Vongsavat, V.; Vittur, B.M.; Bryan, W.W.; Kim, J.-H.; Lee, T.R. Ultrasmall hollow gold-silver nanoshells with extinctions strongly red-shifted to the near-infrared. ACS Appl. Mater. Interfaces 2011, 3, 3616-3624. [CrossRef] [PubMed]

25. Sra, A.K.; Schaak, R.E. Synthesis of atomically ordered $\mathrm{AuCu}$ and $\mathrm{AuCu}_{3}$ nanocrystals from bimetallic nanoparticle precursors. J. Am. Chem. Soc. 2004, 126, 6667-6672. [CrossRef] [PubMed]

26. Cheng, G.; Hight Walker, A.R. Synthesis and characterization of cobalt/gold bimetallic nanoparticles. J. Magn. Magn. Mater. 2007, 311, 31-35. [CrossRef]

27. Li, J.-F.; Zhang, Y.-J.; Ding, S.-Y.; Panneerselvam, R.; Tian, Z.-Q. Core-shell nanoparticle-enhanced Raman Spectroscopy. Chem. Rev. 2017, 117, 5002-5069. [CrossRef] [PubMed]

28. Petryayeva, E.; Krull, U.J. Localized surface Plasmon resonance: Nanostructures, bioassays and biosensing-A Review. Anal. Chim. Acta 2011, 706, 8-24. [CrossRef] [PubMed]

29. Mayer, K.M.; Hafner, J.H. Localized surface Plasmon resonance sensors. Chem. Rev. 2011, 111, 3828-3857. [CrossRef] [PubMed]

30. Wang, X.; Feng, J.; Bai, Y.; Zhang, Q.; Yin, Y. Synthesis, properties, and applications of hollow micro-/nanostructures. Chem. Rev. 2016, 116, 10983-11060. [CrossRef] [PubMed]

31. Alexiou, C.; Jurgons, R.; Schmid, R.; Hilpert, A.; Bergemann, C.; Parak, F.; Iro, H. In vitro and in vivo investigations of targeted chemotherapy with magnetic nanoparticles. J. Magn. Magn. Mater. 2005, 293, 389-393. [CrossRef]

32. Demers, L.M.; Oestblom, M.; Zhang, H.; Jang, N.-H.; Liedberg, B.; Mirkin, C.A. Thermal desorption behavior and binding properties of DNA bases and nucleosides on gold. J. Am. Chem. Soc. 2002, 124, 11248-11249. [CrossRef] [PubMed]

33. Hoffman, A.S. Hydrogels for biomedical applications. Adv. Drug Deliv. Rev. 2002, 54, 3-12. [CrossRef]

34. Gao, J.; Liang, G.; Cheung, J.S.; Pan, Y.; Kuang, Y.; Zhao, F.; Zhang, B.; Zhang, X.; Wu, E.X.; Xu, B. Multifunctional yolk-shell nanoparticles: A potential MRI contrast and anticancer agent. J. Am. Chem. Soc. 2008, 130, 11828-11833. [CrossRef] [PubMed]

35. Lane, L.A.; Qian, X.; Nie, S. SERS Nanoparticles in medicine: From label-free detection to spectroscopic tagging. Chem. Rev. 2015, 115, 10489-10529. [CrossRef] [PubMed]

36. Weissleder, R. A clearer vision for in vivo imaging. Nat. Biotechnol. 2001, 19, 316-317. [CrossRef] [PubMed]

37. Yoo, D.; Lee, J.-H.; Shin, T.-H.; Cheon, J. Theranostic magnetic nanoparticles. Acc. Chem. Res. 2011, 44, 863-874. [CrossRef] [PubMed]

38. Kolhatkar, A.; Jamison, A.C.; Litvinov, D.; Willson, R.; Lee, T. Tuning the magnetic properties of nanoparticles. Int. J. Mol. Sci. 2013, 14, 15977-16009. [CrossRef] [PubMed]

39. Xu, Y.H.; Bai, J.; Wang, J.-P. High-magnetic-moment multifunctional nanoparticles for nanomedicine applications. J. Magn. Magn. Mater. 2007, 311, 131-134. [CrossRef]

40. Yin, S.; Li, Z.; Cheng, L.; Wang, C.; Liu, Y.; Chen, Q.; Gong, H.; Guo, L.; Li, Y.; Liu, Z. Magnetic PEGylated $\mathrm{Pt}_{3} \mathrm{Co}$ nanoparticles as a novel MR contrast agent: In vivo MR imaging and long-term toxicity study. Nanoscale 2013, 5, 12464-12473. [CrossRef] [PubMed]

41. Bansmann, J.; Baker, S.H.; Binns, C.; Blackman, J.A.; Bucher, J.P.; Dorantes-Dávila, J.; Dupuis, V.; Favre, L.; Kechrakos, D.; Kleibert, A.; et al. Magnetic and structural properties of isolated and assembled clusters. Surf. Sci. Rep. 2005, 56, 189-275. [CrossRef]

42. Jeong, U.; Teng, X.; Yong, W.; Yang, H.; Xia, Y. Superparamagnetic colloids: Controlled synthesis and niche applications. Adv. Mater. 2007, 19, 33-60. [CrossRef]

43. Sharma, G.; Gupta, V.K.; Agarwal, S.; Kumar, A.; Thakur, S.; Pathania, D. Fabrication and characterization of Fe@MoPO Nanoparticles: Ion exchange behavior and photocatalytic activity against malachite green. J. Mol. Liq. 2016, 219, 1137-1143. [CrossRef]

44. Zaleska-Medynska, A.; Marchelek, M.; Diak, M.; Grabowska, E. Noble metal-based bimetallic nanoparticles: The effect of the structure on the optical, catalytic and photocatalytic properties. Adv. Colloid Interface Sci. 2016, 229, 80-107. [CrossRef] [PubMed] 
45. Ferrando, R.; Jellinek, J.; Johnston, R.L. Nanoalloys: From theory to applications of alloy clusters and nanoparticles. Chem. Rev. 2008, 108, 845-910. [CrossRef] [PubMed]

46. Daněk, V. Physico-Chemical Analysis of Molten Electrolytes; Elsevier Science: New York, NY, USA, 2006.

47. Riccardo, F. Symmetry breaking and morphological instabilities in core-shell metallic nanoparticles. J. Phys. Condens. Matter 2015, 27, 013003.

48. Langlois, C.; Li, Z.L.; Yuan, J.; Alloyeau, D.; Nelayah, J.; Bochicchio, D.; Ferrando, R.; Ricolleau, C. Transition from core-shell to Janus chemical configuration for bimetallic nanoparticles. Nanoscale 2012, 4, 3381-3388. [CrossRef] [PubMed]

49. Baletto, F.; Mottet, C.; Ferrando, R. Growth of three-shell Onionlike bimetallic nanoparticles. Phys. Rev. Lett. 2003, 90, 135504. [CrossRef] [PubMed]

50. Ferrer, D.; Torres-Castro, A.; Gao, X.; Sepulveda-Guzman, S.; Ortiz-Mendez, U.; Jose-Yacaman, M. Three-Layer core/shell structure in Au-Pd bimetallic nanoparticles. Nano Lett. 2007, 7, 1701-1705. [CrossRef] [PubMed]

51. Xia, Y.; Xia, X.; Peng, H.-C. Shape-controlled synthesis of colloidal metal nanocrystals: Thermodynamic versus kinetic products. J. Am. Chem. Soc. 2015, 137, 7947-7966. [CrossRef] [PubMed]

52. Yawen, W.; Jiating, H.; Cuicui, L.; Han, C.W.; Hongyu, C. Thermodynamics versus kinetics in nanosynthesis. Angew. Chem. Int. Ed. 2015, 54, 2022-2051.

53. Gaffet, E.; Tachikart, M.; El Kedim, O.; Rahouadj, R. Nanostructural materials formation by mechanical alloying: Morphologic analysis based on transmission and scanning electron microscopic observations. Mater. Charact. 1996, 36, 185-190. [CrossRef]

54. Klabunde, K.J. Nanoscale Materials in Chemistry; Wiley-Interscience: Hoboken, NJ, USA, 2001.

55. Hu, J.-W.; Li, J.-F.; Ren, B.; Wu, D.-Y.; Sun, S.-G.; Tian, Z.-Q. Palladium-coated gold nanoparticles with a controlled shell thickness used as surface-enhanced Raman scattering substrate. J. Phys. Chem. C 2007, 111, 1105-1112. [CrossRef]

56. Link, S.; Wang, Z.L.; El-Sayed, M.A. Alloy formation of gold-silver nanoparticles and the dependence of the Plasmon absorption on their composition. J. Phys. Chem. B 1999, 103, 3529-3533. [CrossRef]

57. Sagitha, P.; Sarada, K.; Muraleedharan, K. One-pot synthesis of Poly Vinyl Alcohol (PVA) supported silver nanoparticles and its efficiency in catalytic reduction of methylene blue. Trans. Nonferr. Met. Soc. China 2016, 26, 2693-2700. [CrossRef]

58. Toshima, N.; Harada, M.; Yamazaki, Y.; Asakura, K. Catalytic activity and structural analysis of polymer-protected gold-palladium bimetallic clusters prepared by the simultaneous reduction of hydrogen Tetrachloroaurate and palladium dichloride. J. Phys. Chem. 1992, 96, 9927-9933. [CrossRef]

59. Mizukoshi, Y.; Okitsu, K.; Maeda, Y.; Yamamoto, T.A.; Oshima, R.; Nagata, Y. Sonochemical preparation of bimetallic nanoparticles of gold/palladium in aqueous solution. J. Phys. Chem. B 1997, 101, 7033-7037. [CrossRef]

60. Kan, C.; Cai, W.; Li, C.; Zhang, L.; Hofmeister, H. Ultrasonic synthesis and optical properties of Au/Pd bimetallic nanoparticles in ethylene glycol. J. Phys. D Appl. Phys. 2003, 36, 1609-1614. [CrossRef]

61. Vasquez, Y.; Luo, Z.; Schaak, R.E. Low-temperature solution synthesis of the non-equilibrium ordered intermetallic compounds $\mathrm{Au}_{3} \mathrm{Fe}, \mathrm{Au}_{3} \mathrm{Co}$, and $\mathrm{Au}_{3} \mathrm{Ni}$ as nanocrystals. J. Am. Chem. Soc. 2008, 130, 11866-11867. [CrossRef] [PubMed]

62. Ueji, M.; Harada, M.; Kimura, Y. Synthesis of Pt/Ru bimetallic nanoparticles in high-temperature and high-pressure fluids. J. Colloid Interface Sci. 2008, 322, 358-363. [CrossRef] [PubMed]

63. Harpeness, R.; Gedanken, A. Microwave synthesis of core-shell gold/palladium bimetallic nanoparticles. Langmuir 2004, 20, 3431-3434. [CrossRef] [PubMed]

64. Treguer, M.; De Cointet, C.; Remita, H.; Khatouri, J.; Mostafavi, M.; Amblard, J.; Belloni, J.; De Keyzer, R. Dose rate effects on radiolytic synthesis of gold-silver bimetallic clusters in solution. J. Phys. Chem. B 1998, 102, 4310-4321. [CrossRef]

65. Hund, J.F.; Bertino, M.F.; Zhang, G.; Sotiriou-Leventis, C.; Leventis, N. Synthesis of homogeneous alloy metal nanoparticles in silica aerogels. J. Non-Cryst. Solids 2004, 350, 9-13. [CrossRef]

66. Schmid, G.L.A.; Malm, J.-O.; Bovin, J.-O. Ligand-stabilized bimetallic colloids identified by HRTEM and EDX. Angew. Chem. Int. Ed. 1991, 30, 874-876. [CrossRef]

67. Lee, P.C.; Meisel, D. Adsorption and surface-enhanced Raman of dyes on silver and gold sols. J. Phys. Chem. 1982, 86, 3391-3395. [CrossRef] 
68. Nadagouda, M.N.; Varma, R.S. A greener synthesis of core (Fe, Cu)-Shell (Au, Pt, Pd, and Ag) nanocrystals using aqueous vitamin C. Cryst. Growth Des. 2007, 7, 2582-2587. [CrossRef]

69. Skrabalak, S.E.; Chen, J.; Sun, Y.; Lu, X.; Au, L.; Cobley, C.M.; Xia, Y. Gold nanocages: Synthesis, properties, and applications. Acc. Chem. Res. 2008, 41, 1587-1595. [CrossRef] [PubMed]

70. Yang, J.; Lee, J.Y.; Too, H.-P. Core-shell Ag-Au nanoparticles from replacement reaction in organic medium. J. Phys. Chem. B 2005, 109, 19208-19212. [CrossRef] [PubMed]

71. Naha, P.C.; Lau, K.C.; Hsu, J.C.; Hajfathalian, M.; Mian, S.; Chhour, P.; Uppuluri, L.; Mcdonald, E.S.; Maidment, A.D.A.; Cormode, D.P. Gold Silver Alloy Nanoparticles (GSAN): An imaging probe for breast cancer screening with dual-energy mammography or computed tomography. Nanoscale 2016, 8, 13740-13754. [CrossRef] [PubMed]

72. Cho, E.C.; Kim, C.; Zhou, F.; Cobley, C.M.; Song, K.H.; Chen, J.; Li, Z.-Y.; Wang, L.V.; Xia, Y. Measuring the optical absorption cross sections of $\mathrm{Au}-\mathrm{Ag}$ Nanocages and Au Nanorods by Photoacoustic imaging. J. Phys. Chem. C 2009, 113, 9023-9028. [CrossRef] [PubMed]

73. Srnova-Sloufova, I.; Lednicky, F.; Gemperle, A.; Gemperlova, J. Core-Shell (Ag)Au bimetallic nanoparticles: Analysis of transmission electron microscopy images. Langmuir 2000, 16, 9928-9935. [CrossRef]

74. Park, G.; Seo, D.; Jung, J.; Ryu, S.; Song, H. Shape evolution and gram-scale synthesis of Gold@Silver Core-shell Nanopolyhedrons. J. Phys. Chem. C 2011, 115, 9417-9423. [CrossRef]

75. Fu, J.; Wang, S.; Zhu, J.; Wang, K.; Gao, M.; Wang, X.; Xu, Q. Au-Ag bimetallic nanoparticles decorated multi-amino Cyclophosphazene hybrid microspheres as enhanced activity catalysts for the reduction of 4-nitrophenol. Mater. Chem. Phys. 2018, 207, 315-324. [CrossRef]

76. Kim, W.; Lee, J.-C.; Lee, G.-J.; Park, H.-K.; Lee, A.; Choi, S. Low-cost label-free biosensing bimetallic cellulose strip with SILAR-synthesized silver core-gold shell nanoparticle structures. Anal. Chem. 2017, 89, 6448-6454. [CrossRef] [PubMed]

77. Dahal, N.; Chikan, V.; Jasinski, J.; Leppert, V.J. Synthesis of water-soluble iron-gold alloy nanoparticles. Chem. Mater. 2008, 20, 6389-6395. [CrossRef]

78. Amendola, V.; Meneghetti, M.; Bakr, O.M.; Riello, P.; Polizzi, S.; Anjum, D.H.; Fiameni, S.; Arosio, P.; Orlando, T.; De Julian Fernandez, C.; Pineider, F.; Sangregorio, C.; Lascialfari, A. Coexistence of Plasmonic and magnetic properties in $\mathrm{Au}_{89} \mathrm{Fe}_{11}$ nanoalloys. Nanoscale 2013, 5, 5611-5619. [CrossRef] [PubMed]

79. Amendola, V.; Scaramuzza, S.; Litti, L.; Meneghetti, M.; Zuccolotto, G.; Rosato, A.; Nicolato, E.; Marzola, P.; Fracasso, G.; Anselmi, C.; Pinto, M.; Colombatti, M. Magneto-Plasmonic Au-Fe alloy nanoparticles designed for multimodal SERS-MRI-CT Imaging. Small 2014, 10, 2476-2486. [CrossRef] [PubMed]

80. Lu, Z.; Prouty, M.D.; Guo, Z.; Golub, V.O.; Kumar, C.S.S.R.; Lvov, Y.M. Magnetic switch of permeability for polyelectrolyte microcapsules embedded with Co@Au nanoparticles. Langmuir 2005, 21, 2042-2050. [CrossRef] [PubMed]

81. Boyer, P.; Ménard, D.; Meunier, M. Nanoclustered Co-Au particles fabricated by femtosecond laser fragmentation in liquids. J. Phys. Chem. C 2010, 114, 13497-13500. [CrossRef]

82. Swiatkowska-Warkocka, Z.; Koga, K.; Kawaguchi, K.; Wang, H.; Pyatenko, A.; Koshizaki, N. Pulsed laser irradiation of colloidal nanoparticles: A new synthesis route for the production of non-equilibrium bimetallic alloy submicrometer spheres. RSC Adv. 2013, 3, 79-83. [CrossRef]

83. Salem, A.K.; Searson, P.C.; Leong, K.W. Multifunctional nanorods for gene delivery. Nat. Mater. 2003, 2, 668. [CrossRef] [PubMed]

84. Su, C.-H.; Sheu, H.-S.; Lin, C.-Y.; Huang, C.-C.; Lo, Y.-W.; Pu, Y.-C.; Weng, J.-C.; Shieh, D.-B.; Chen, J.-H.; Yeh, C.-S. Nanoshell magnetic resonance imaging contrast agents. J. Am. Chem. Soc. 2007, 129, 2139-2146. [CrossRef] [PubMed]

85. Belousov, O.V.; Belousova, N.V.; Sirotina, A.V.; Solovyov, L.A.; Zhyzhaev, A.M.; Zharkov, S.M.; Mikhlin, Y.L. Formation of Bimetallic $\mathrm{Au}-\mathrm{Pd}$ and $\mathrm{Au}-\mathrm{Pt}$ nanoparticles under hydrothermal conditions and microwave irradiation. Langmuir 2011, 27, 11697-11703. [CrossRef] [PubMed]

86. Mizukoshi, Y.; Fujimoto, T.; Nagata, Y.; Oshima, R.; Maeda, Y. Characterization and catalytic activity of core-shell structured gold/palladium bimetallic nanoparticles synthesized by the sonochemical method. J. Phys. Chem. B 2000, 104, 6028-6032. [CrossRef]

87. Okitsu, K.; Murakami, M.; Tanabe, S.; Matsumoto, H. Catalytic behavior of Au Core/Pd shell bimetallic nanoparticles on silica prepared by sonochemical and sol-gel processes. Chem. Lett. 2000, 29, 1336-1337. [CrossRef] 
88. Hu, J.-W.; Zhang, Y.; Li, J.-F.; Liu, Z.; Ren, B.; Sun, S.-G.; Tian, Z.-Q.; Lian, T. Synthesis of Au@Pd core-shell nanoparticles with controllable size and their application in surface-enhanced Raman spectroscopy. Chem. Phys. Lett. 2005, 408, 354-359. [CrossRef]

89. Zhan, G.; Huang, J.; Du, M.; Abdul-Rauf, I.; Ma, Y.; Li, Q. Green synthesis of Au-Pd bimetallic nanoparticles: Single-step bioreduction method with plant extract. Mater. Lett. 2011, 65, 2989-2991. [CrossRef]

90. Fan, F.; Zhang, J.; Li, J.; Zhang, N.; Hong, R.; Deng, X.; Tang, P.; Li, D. Hydrogen sensing properties of Pt-Au bimetallic nanoparticles loaded on ZnO Nanorods. Sens. Actuators B Chem. 2017, 241, 895-903. [CrossRef]

91. Ye, W.; Yu, J.; Zhou, Y.; Gao, D.; Wang, D.; Wang, C.; Xue, D. Green synthesis of Pt-Au dendrimer-like nanoparticles supported on Polydopamine-functionalized Graphene and their high performance toward 4-Nitrophenol reduction. Appl. Catal. B Environ. 2016, 181, 371-378. [CrossRef]

92. Li, H.; Wu, H.; Zhai, Y.; Xu, X.; Jin, Y. Synthesis of monodisperse plasmonic Au Core-Pt shell concave Nanocubes with superior catalytic and Electrocatalytic activity. ACS Catal. 2013, 3, 2045-2051. [CrossRef]

93. Selvakannan, P.R.; Sastry, M. Hollow gold and platinum nanoparticles by a transmetallation reaction in an organic solution. Chem. Commun. 2005, 1684-1686. [CrossRef] [PubMed]

94. Wang, C.; Tian, W.; Ding, Y.; Ma, Y.-Q.; Wang, Z.L.; Markovic, N.M.; Stamenkovic, V.R.; Daimon, H.; Sun, S. Rational synthesis of heterostructured nanoparticles with morphology control. J. Am. Chem. Soc. 2010, 132, 6524-6529. [CrossRef] [PubMed]

95. Yang, Q.; Peng, J.; Xiao, Y.; Li, W.; Tan, L.; Xu, X.; Qian, Z. Porous Au@Pt Nanoparticles: Therapeutic platform for tumor chemo-photothermal Co-Therapy and alleviating doxorubicin-induced oxidative damage. ACS Appl. Mater. Interfaces 2018, 10, 150-164. [CrossRef] [PubMed]

96. Krishnan, S.K.; Prokhorov, E.; Bahena, D.; Esparza, R.; Meyyappan, M. Chitosan-Covered Pd@Pt core-shell nanocubes for direct electron transfer in electrochemical enzymatic glucose biosensor. ACS Omega 2017, 2, 1896-1904. [CrossRef]

97. Fujimoto, T.; Terauchi, S.-Y.; Umehara, H.; Kojima, I.; Henderson, W. Sonochemical preparation of single-dispersion metal nanoparticles from metal salts. Chem. Mater. 2001, 13, 1057-1060. [CrossRef]

98. Chen, J.; Wiley, B.; Mclellan, J.; Xiong, Y.; Li, Z.-Y.; Xia, Y. Optical Properties of Pd-Ag and Pt-Ag nanoboxes synthesized via galvanic replacement reactions. Nano Lett. 2005, 5, 2058-2062. [CrossRef] [PubMed]

99. Doudna, C.M.; Bertino, M.F.; Blum, F.D.; Tokuhiro, A.T.; Lahiri-Dey, D.; Chattopadhyay, S.; Terry, J. Radiolytic synthesis of bimetallic Ag-Pt nanoparticles with a high aspect ratio. J. Phys. Chem. B 2003, 107, 2966-2970. [CrossRef]

100. Jiang, B.; Kani, K.; Iqbal, M.; Abe, H.; Kimura, T.; Hossain, M.S.A.; Anjaneyulu, O.; Henzie, J.; Yamauchi, Y. Mesoporous bimetallic $\mathrm{RhCu}$ alloy nanospheres using a sophisticated soft-templating strategy. Chem. Mater. 2018, 30, 428-435. [CrossRef]

101. Mancier, V.; Rousse-Bertrand, C.; Dille, J.; Michel, J.; Fricoteaux, P. Sono and electrochemical synthesis and characterization of copper core-silver shell nanoparticles. Ultrason. Sonochem. 2010, 17, 690-696. [CrossRef] [PubMed]

102. Chou, S.-W.; Liu, C.-L.; Liu, T.-M.; Shen, Y.-F.; Kuo, L.-C.; Wu, C.-H.; Hsieh, T.-Y.; Wu, P.-C.; Tsai, M.-R.; Yang, C.-C.; et al. Infrared-active quadruple contrast FePt nanoparticles for multiple scale molecular imaging. Biomaterials 2016, 85, 54-64. [CrossRef] [PubMed]

103. Maenosono, S.; Suzuki, T.; Saita, S. Superparamagnetic FePt nanoparticles as excellent MRI contrast agents. J. Magn. Magn. Mater. 2008, 320, 79-83. [CrossRef]

104. Chen, C.-L.; Kuo, L.-R.; Lee, S.-Y.; Hwu, Y.-K.; Chou, S.-W.; Chen, C.-C.; Chang, F.-H.; Lin, K.-H.; Tsai, D.-H.; Chen, Y.-Y. Photothermal cancer therapy via femtosecond-laser-excited FePt nanoparticles. Biomaterials 2013, 34, 1128-1134. [CrossRef] [PubMed]

105. Yang, H.; Zhang, J.; Tian, Q.; Hu, H.; Fang, Y.; Wu, H.; Yang, S. One-pot synthesis of amphiphilic superparamagnetic FePt nanoparticles and magnetic resonance imaging in vitro. J. Magn. Magn. Mater. 2010, 322, 973-977. [CrossRef]

106. Chou, S.-W.; Shau, Y.-H.; Wu, P.-C.; Yang, Y.-S.; Shieh, D.-B.; Chen, C.-C. In vitro and in vivo studies of FePt nanoparticles for dual modal CT/MRI molecular imaging. J. Am. Chem. Soc. 2010, 132, 13270-13278. [CrossRef] [PubMed]

107. Fuchigami, T.; Kawamura, R.; Kitamoto, Y.; Nakagawa, M.; Namiki, Y. Ferromagnetic FePt-nanoparticles/polycation hybrid capsules designed for a magnetically guided drug delivery system. Langmuir 2011, 27, 2923-2928. [CrossRef] [PubMed] 
108. Wang, J.; Loh, K.P.; Zhong, Y.L.; Lin, M.; Ding, J.; Foo, Y.L. Bifunctional FePt core-shell and hollow Spheres: Sonochemical preparation and self-assembly. Chem. Mater. 2007, 19, 2566-2572. [CrossRef]

109. Sahu, N.K.; Gupta, J.; Bahadur, D. PEGylated FePt-Fe $\mathrm{O}_{4}$ Composite Nanoassemblies (CNAs): In vitro hyperthermia, drug delivery and generation of Reactive Oxygen Species (ROS). Dalton Trans. 2015, 44, 9103-9113. [CrossRef] [PubMed]

110. An, L.; Yu, Y.; Li, X.; Liu, W.; Yang, H.; Wu, D.; Yang, S. Dextran-coated Superparamagnetic amorphous Fe-Co nanoalloy for magnetic resonance imaging applications. Mater. Res. Bull. 2014, 49, 285-290. [CrossRef]

111. Seo, W.S.; Lee, J.H.; Sun, X.; Suzuki, Y.; Mann, D.; Liu, Z.; Terashima, M.; Yang, P.C.; Mcconnell, M.V.; Nishimura, D.G.; Dai, H. FeCo/graphitic-shell Nanocrystals as advanced magnetic-resonance-imaging and near-infrared agents. Nat. Mater. 2006, 5, 971-976. [CrossRef] [PubMed]

112. Li, Y.; Srinivasan, B.; Jing, Y.; Yao, X.; Hugger, M.A.; Wang, J.-P.; Xing, C. Nanomagnetic competition assay for low-abundance protein biomarker quantification in unprocessed human sera. J. Am. Chem. Soc. 2010, 132, 4388-4392. [CrossRef] [PubMed]

113. Balasubramanian, S.; Yuanpeng, L.; Ying, J.; Yunhao, X.; Xiaofeng, Y.; Chengguo, X.; Jian-Ping, W. A detection system based on giant magnetoresistive sensors and high-moment magnetic nanoparticles demonstrates Zeptomole sensitivity: Potential for personalized medicine. Angew. Chem. Int. Ed. 2009, 48, 2764-2767.

114. Cui, B.Z.; Marinescu, M.; Liu, J.F. High magnetization Fe-Co and Fe-Ni submicron and nanosize particles by thermal decomposition and hydrogen reduction. J. Appl. Phys. 2014, 115, 17A315. [CrossRef]

115. Yang, H.; Li, X.; Zhou, H.; Zhuang, Y.; Hu, H.; Wu, H.; Yang, S. Monodisperse water-soluble Fe-Ni nanoparticles for magnetic resonance imaging. J. Alloys Compd. 2011, 509, 1217-1221. [CrossRef]

116. Shevchenko, E.V.; Talapin, D.V.; Schnablegger, H.; Kornowski, A.; Festin, O.; Svedlindh, P.; Haase, M.; Weller, H. Study of nucleation and growth in the organometallic synthesis of magnetic alloy nanocrystals: The role of nucleation rate in size control of $\mathrm{CoPt}_{3}$ Nanocrystals. J. Am. Chem. Soc. 2003, 125, 9090-9101. [CrossRef] [PubMed]

117. Cai, S.; Qi, C.; Li, Y.; Han, Q.; Yang, R.; Wang, C. PtCo Bimetallic nanoparticles with high oxidase-like catalytic activity and their applications for magnetic-enhanced colorimetric biosensing. J. Mater. Chem. B 2016, 4, 1869-1877. [CrossRef]

118. Huang, X.; Tang, S.; Liu, B.; Ren, B.; Zheng, N. Enhancing the photothermal stability of plasmonic metal nanoplates by a core-shell architecture. Adv. Mater. 2011, 23, 3420-3425. [CrossRef] [PubMed]

119. Ban, I.; Stergar, J.; Drofenik, M.; Ferk, G.; Makovec, D. Synthesis of copper-nickel nanoparticles prepared by mechanical milling for use in magnetic hyperthermia. J. Magn. Magn. Mater. 2011, 323, 2254-2258. [CrossRef]

120. Gilroy, K.D.; Ruditskiy, A.; Peng, H.-C.; Qin, D.; Xia, Y. Bimetallic nanocrystals: Syntheses, properties, and applications. Chem. Rev. 2016, 116, 10414-10472. [CrossRef] [PubMed]

121. Nakao, Y. Preparation of a gold organosol in chloroform and its discolouration by photoirradiation. J. Chem. Soc. Chem. Commun. 1994, 2067-2068. [CrossRef]

122. Nath, S.; Jana, S.; Pradhan, M.; Pal, T. Ligand-stabilized metal nanoparticles in organic solvent. J. Colloid Interface Sci. 2010, 341, 333-352. [CrossRef] [PubMed]

123. Murray, C.B.; Kagan, C.R.; Bawendi, M.G. Synthesis and characterization of monodisperse nanocrystals and close-packed nanocrystal assemblies. Annu. Rev. Mater. Sci. 2000, 30, 545-610. [CrossRef]

124. Radjala, T.R.H.; Apostolescu, G.; Mostafavi, M.; Thomazeau, C.; Uzio, D. Bimetallic Au-Pd and Ag-Pd Clusters Synthesised by $\gamma$ or Electron Beam Radiolysis and Study of the Reactivity/Structure Relationships in the Selective Hydrogenation of Buta-1,3-Diene. Oil Gas J. 2006, 61, 789. [CrossRef]

125. Mulvaney, P.; Giersig, M.; Henglein, A. Electrochemistry of multilayer colloids: Preparation and absorption spectrum of gold-coated silver particles. J. Phys. Chem. 1993, 97, 7061-7064. [CrossRef]

126. Henglein, A. Colloidal palladium nanoparticles. Reduction of $\mathrm{Pd}(\mathrm{II})$ by $\mathrm{H}_{2} ; \mathrm{Pd}_{\text {core }} \mathrm{Au}_{\text {shell }} \mathrm{Ag}_{\text {shell }} \mathrm{Particles}$. J. Phys. Chem. B 2000, 104, 6683-6685. [CrossRef]

127. Wang, H.; Pyatenko, A.; Kawaguchi, K.; Li, X.; Swiatkowska-Warkocka, Z.; Koshizaki, N. Selective pulsed heating for the synthesis of semiconductor and metal Submicrometer spheres. Angew. Chem. Int. Ed. 2010, 49, 6361-6364. [CrossRef] [PubMed]

128. Wang, R.; Hughes, T.; Beck, S.; Vakil, S.; Li, S.; Pantano, P.; Draper, R.K. Generation of toxic degradation products by sonication of Pluronic ${ }^{\circledR}$ Dispersants: Implications for nanotoxicity testing. Nanotoxicology 2013, 7, 1272-1281. [CrossRef] [PubMed] 
129. Xu, H.; Zeiger, B.W.; Suslick, K.S. Sonochemical synthesis of nanomaterials. Chem. Soc. Rev. 2013, 42, 2555-2567. [CrossRef] [PubMed]

130. Jia, Y.; Niu, H.; Wu, M.; Ning, M.; Zhu, H.; Chen, Q. Sonochemical preparation of bimetallic Co/Cu nanoparticles in aqueous solution. Mater. Res. Bull. 2005, 40, 1623-1629. [CrossRef]

131. Xia, Y.; Gilroy, K.D.; Peng, H.-C.; Xia, X. Seed-mediated growth of colloidal metal nanocrystals. Angew. Chem. Int. Ed. 2017, 56, 60-95. [CrossRef] [PubMed]

132. Niu, W.; Zhang, L.; Xu, G. Seed-mediated growth of noble metal nanocrystals: Crystal growth and shape control. Nanoscale 2013, 5, 3172-3181. [CrossRef] [PubMed]

133. Mcgilvray, K.L.; Fasciani, C.; Bueno-Alejo, C.J.; Schwartz-Narbonne, R.; Scaiano, J.C. Photochemical strategies for the seed-mediated growth of gold and gold-silver nanoparticles. Langmuir 2012, 28, 16148-16155. [CrossRef] [PubMed]

134. Jana, N.R.; Gearheart, L.; Murphy, C.J. Seeding growth for size control of 5-40 nm diameter gold nanoparticles. Langmuir 2001, 17, 6782-6786. [CrossRef]

135. Roduner, E. Size Matters: Why nanomaterials are different. Chem. Soc. Rev. 2006, 35, 583-592. [CrossRef] [PubMed]

136. Chen, L.Y.; Chen, N.; Hou, Y.; Wang, Z.C.; Lv, S.H.; Fujita, T.; Jiang, J.H.; Hirata, A.; Chen, M.W. Geometrically controlled nanoporous $\mathrm{PdAu}$ bimetallic catalysts with tunable $\mathrm{Pd} / \mathrm{Au}$ ratio for direct ethanol fuel cells. ACS Catal. 2013, 3, 1220-1230. [CrossRef]

137. Dai, L.; Song, L.; Huang, Y.; Zhang, L.; Lu, X.; Zhang, J.; Chen, T. Bimetallic Au/Ag core-shell superstructures with tunable surface plasmon resonance in the near-infrared region and high performance surface-enhanced Raman scattering. Langmuir 2017, 33, 5378-5384. [CrossRef] [PubMed]

138. Singh, V.; Cassidy, C.; Grammatikopoulos, P.; Djurabekova, F.; Nordlund, K.; Sowwan, M. Heterogeneous gas-phase synthesis and molecular dynamics modeling of Janus and core-satellite Si-Ag nanoparticles. J. Phys. Chem. C 2014, 118, 13869-13875. [CrossRef]

139. Wilson, O.M.; Scott, R.W.J.; Garcia-Martinez, J.C.; Crooks, R.M. Synthesis, characterization, and structure-selective extraction of 1-3-nm diameter AuAg Dendrimer-encapsulated bimetallic nanoparticles. J. Am. Chem. Soc. 2005, 127, 1015-1024. [CrossRef] [PubMed]

140. Sheny, D.S.; Mathew, J.; Philip, D. Phytosynthesis of Au, Ag and Au-Ag bimetallic nanoparticles using aqueous extract and dried leaf of anacardium occidentale. Spectrochim. Acta A 2011, 79, 254-262. [CrossRef] [PubMed]

141. Philip, D. Biosynthesis of $\mathrm{Au}, \mathrm{Ag}$ and $\mathrm{Au}-\mathrm{Ag}$ nanoparticles using edible mushroom extract. Spectrochim. Acta A 2009, 73, 374-381. [CrossRef] [PubMed]

142. Meena Kumari, M.; Jacob, J.; Philip, D. Green synthesis and applications of Au-Ag bimetallic nanoparticles. Spectrochim. Acta A 2015, 137, 185-192. [CrossRef] [PubMed]

143. Raju, D.; Mendapara, R.; Mehta, U.J. Protein mediated synthesis of Au-Ag bimetallic nanoparticles. Mater. Lett. 2014, 124, 271-274. [CrossRef]

144. Castro-Longoria, E.; Vilchis-Nestor, A.R.; Avalos-Borja, M. Biosynthesis of silver, gold and bimetallic nanoparticles using the filamentous fungus Neurospora Crassa. Colloids Surf. B. Biointerfaces 2011, 83, 42-48. [CrossRef] [PubMed]

145. Ding, L.-X.; Wang, A.-L.; Li, G.-R.; Liu, Z.-Q.; Zhao, W.-X.; Su, C.-Y.; Tong, Y.-X. Porous Pt-Ni-P Composite Nanotube Arrays: Highly electroactive and durable catalysts for methanol electrooxidation. J. Am. Chem. Soc. 2012, 134, 5730-5733. [CrossRef] [PubMed]

146. Guler, M.; Turkoglu, V.; Bulut, A.; Zahmakiran, M. Electrochemical sensing of hydrogen peroxide using Pd@Ag bimetallic nanoparticles decorated functionalized reduced graphene oxide. Electrochim. Acta 2018, 263, 118-126. [CrossRef]

147. Hierrezuelo, J.; Sadeghpour, A.; Szilagyi, I.; Vaccaro, A.; Borkovec, M. Electrostatic stabilization of charged colloidal particles with adsorbed polyelectrolytes of opposite charge. Langmuir 2010, 26, 15109-15111. [CrossRef] [PubMed]

148. Faraday, M. The bakerian lecture: experimental relations of gold (and other metals) to light. Philos. Trans. 1857, 147, 145. [CrossRef]

149. Yin, Y.; Li, Z.-Y.; Zhong, Z.; Gates, B.; Xia, Y.; Venkateswaran, S. Synthesis and characterization of stable aqueous dispersions of silver nanoparticles through the Tollens process. J. Mater. Chem. 2002, 12, 522-527. [CrossRef] 
150. Cao, G. Nanostructures \& Nanometerials Synthesis, Properties \& Applications; Imperial College Press: London, UK, 2004.

151. Murphy, C.J.; Sau, T.K.; Gole, A.M.; Orendorff, C.J.; Gao, J.; Gou, L.; Hunyadi, S.E.; Li, T. Anisotropic metal nanoparticles: Synthesis, assembly, and optical applications. J. Phys. Chem. B 2005, 109, 13857-13870. [CrossRef] [PubMed]

152. Wiley, B.; Herricks, T.; Sun, Y.; Xia, Y. Polyol synthesis of silver nanoparticles: Use of chloride and oxygen to promote the formation of single-crystal, truncated cubes and tetrahedrons. Nano Lett. 2004, 4, 1733-1739. [CrossRef]

153. Zheng, P.; Jiang, X.; Zhang, X.; Zhang, W.; Shi, L. Formation of Gold@Polymer core-shell particles and gold particle clusters on a template of thermoresponsive and $\mathrm{pH}$-responsive coordination Triblock copolymer. Langmuir 2006, 22, 9393-9396. [CrossRef] [PubMed]

154. Mcnamara, K.; Tofail, S.A.M. Nanoparticles in biomedical applications. Adv. Phys. 2017, 2, 54-88. [CrossRef]

155. Dutta, D.; Chattopadhyay, A.; Ghosh, S.S. Cationic BSA Templated Au-Ag bimetallic nanoclusters as a theranostic gene delivery vector for Hela cancer cells. ACS Biomater. Sci. Eng. 2016, 2, 2090-2098. [CrossRef]

156. Rick, J.; Tsai, M.-C.; Hwang, B. Biosensors incorporating bimetallic nanoparticles. Nanomaterials 2016, 6, 5. [CrossRef] [PubMed]

157. Lodewijks, K.; Van Roy, W.; Borghs, G.; Lagae, L.; Van Dorpe, P. Boosting the Figure-of-Merit of LSPR-based refractive index sensing by phase-sensitive measurements. Nano Lett. 2012, 12, 1655-1659. [CrossRef] [PubMed]

158. Li, E.Q.; Vakarelski, I.U.; Chan, D.Y.C.; Thoroddsen, S.T. Stabilization of thin liquid films by repulsive van der Waals force. Langmuir 2014, 30, 5162-5169. [CrossRef] [PubMed]

159. Stuart, D.A.; Haes, A.J.; Yonzon, C.R.; Hicks, E.M.; Duyne, R.P.V. Biological applications of localised surface plasmonic phenomenae. IEE Proc. Nanobiotechnol. 2005, 152, 13-32. [CrossRef] [PubMed]

160. Csete, M.; Szalai, A.; Csapó, E.; Tóth, L.; Somogyi, A.; Dékány, I. Collective Plasmonic resonances on arrays of cysteine-functionalized silver nanoparticle aggregates. J. Phys. Chem. C 2014, 118, 17940-17955. [CrossRef]

161. Aili, D.; Selegård, R.; Baltzer, L.; Enander, K.; Liedberg, B. Colorimetric protein sensing by controlled assembly of gold nanoparticles functionalized with synthetic receptors. Small 2009, 5, 2445-2452. [CrossRef] [PubMed]

162. Thanh, N.T.K.; Rosenzweig, Z. Development of an aggregation-based immunoassay for anti-protein a using gold nanoparticles. Anal. Chem. 2002, 74, 1624-1628. [CrossRef] [PubMed]

163. Zhang, F.; Zhu, J.; Li, J.-J.; Zhao, J.-W. A promising direct visualization of an Au@Ag nanorod-based colorimetric sensor for trace detection of alpha-fetoprotein. J. Mater. Chem. C 2015, 3, 6035-6045. [CrossRef]

164. Wang, Y.; Yan, B.; Chen, L. Sers Tags: Novel optical Nanoprobes for Bioanalysis. Chem. Rev. 2013, 113, 1391-1428. [CrossRef] [PubMed]

165. Wang, Z.; Zong, S.; Wu, L.; Zhu, D.; Cui, Y. SERS-activated platforms for immunoassay: Probes, encoding methods, and applications. Chem. Rev. 2017, 117, 7910-7963. [CrossRef] [PubMed]

166. Liu, B.; Ni, H.; Zhang, D.; Wang, D.; Fu, D.; Chen, H.; Gu, Z.; Zhao, X. ultrasensitive detection of protein with wide linear dynamic range based on core-shell SERS nanotags and photonic crystal beads. ACS Sens. 2017, 2, 1035-1043. [CrossRef] [PubMed]

167. Chen, Y.-T.; Kolhatkar, A.G.; Zenasni, O.; Xu, S.; Lee, T.R. Biosensing using magnetic particle detection techniques. Sensors 2017, 17, 2300. [CrossRef] [PubMed]

168. Srinivasan, B.; Li, Y.; Jing, Y.; Xing, C.; Slaton, J.; Wang, J.-P. A three-layer competition-based giant magnetoresistive assay for direct quantification of endoglin from human urine. Anal. Chem. 2011, 83, 2996-3002. [CrossRef] [PubMed]

169. Kolhatkar, A.G.; Nekrashevich, I.; Litvinov, D.; Willson, R.C.; Lee, T.R. Cubic silica-coated and amine-functionalized FeCo nanoparticles with high saturation magnetization. Chem. Mater. 2013, 25, 1092-1097. [CrossRef] [PubMed]

170. Gu, H.; Ho, P.-L.; Wt Tsang, K.; Yu, C.-W.; Xu, B. Using biofunctional magnetic nanoparticles to capture gram-negative bacteria at an ultra-low concentration. Chem. Commun. 2003, 1966-1967. [CrossRef]

171. Gu, H.; Ho, P.-L.; Tsang, K.W.T.; Wang, L.; Xu, B. Using biofunctional magnetic nanoparticles to capture vancomycin-resistant enterococci and other gram-positive bacteria at ultralow concentration. J. Am. Chem. Soc. 2003, 125, 15702-15703. [CrossRef] [PubMed] 
172. Dreaden, E.C.; Alkilany, A.M.; Huang, X.; Murphy, C.J.; El-Sayed, M.A. The golden age: Gold nanoparticles for biomedicine. Chem. Soc. Rev. 2012, 41, 2740-2779. [CrossRef] [PubMed]

173. Song, K.H.; Kim, C.; Cobley, C.M.; Xia, Y.; Wang, L.V. Near-infrared gold nanocages as a new class of tracers for photoacoustic sentinel lymph node mapping on a rat model. Nano Lett. 2009, 9, 183-188. [CrossRef] [PubMed]

174. Jun, Y.-W.; Lee, J.-H.; Cheon, J. Chemical design of nanoparticle probes for high-performance magnetic resonance imaging. Angew. Chem. Int. Ed. 2008, 47, 5122-5135. [CrossRef] [PubMed]

175. Jun, Y.-W.; Huh, Y.-M.; Choi, J.-S.; Lee, J.-H.; Song, H.-T.; Kim, S.; Yoon, S.; Kim, K.-S.; Shin, J.-S.; Suh, J.-S.; Cheon, J. Nanoscale size effect of magnetic nanocrystals and their utilization for cancer diagnosis via magnetic resonance imaging. J. Am. Chem. Soc. 2005, 127, 5732-5733. [CrossRef] [PubMed]

176. Rittikulsittichai, S.; Kolhatkar, A.G.; Sarangi, S.; Vorontsova, M.A.; Vekilov, P.G.; Brazdeikis, A.; Randall Lee, T. Multi-responsive hybrid particles: Thermo-, $\mathrm{pH}-$, Photo-, and magneto-responsive magnetic hydrogel cores with gold nanorod optical triggers. Nanoscale 2016, 8, 11851-11861. [CrossRef] [PubMed]

177. Chen, S.; Wang, L.; Duce, S.L.; Brown, S.; Lee, S.; Melzer, A.; Cuschieri, S.A.; André, P. Engineered biocompatible nanoparticles for in vivo imaging applications. J. Am. Chem. Soc. 2010, 132, 15022-15029. [CrossRef] [PubMed]

178. Choi, J.-S.; Jun, Y.-W.; Yeon, S.-I.; Kim, H.C.; Shin, J.-S.; Cheon, J. Biocompatible heterostructured nanoparticles for multimodal biological detection. J. Am. Chem. Soc. 2006, 128, 15982-15983. [CrossRef] [PubMed]

179. Kumar, C.S.S.R.; Hormes, J.; Leuschner, C. Nanofabrication towards Biomedical Applications; Wiley: Hoboken, NJ, USA, 2005.

180. Paulides, M.M.; Stauffer, P.R.; Neufeld, E.; Maccarini, P.; Kyriakou, A.; Canters, R.A.M.; Diederich, C.; Bakker, J.F.; Van Rhoon, G.C. Simulation techniques in hyperthermia treatment planning. Int. J. Hyperth. Off. J. Eur. Soc. Hyperth. Oncol. N. Am. Hyperth. Group 2013, 29, 346-357. [CrossRef] [PubMed]

181. Baffou, G.; Quidant, R. Thermo-Plasmonics: Using metallic nanostructures as nano-sources of heat. Laser Photonics Rev. 2013, 7, 171-187. [CrossRef]

182. Prevo, B.G.; Esakoff, S.A.; Mikhailovsky, A.; Zasadzinski, J.A. Scalable routes to gold nanoshells with tunable sizes and response to near-infrared pulsed-laser irradiation. Small 2008, 4, 1183-1195. [CrossRef] [PubMed]

183. Cheng, L.; Wang, C.; Feng, L.; Yang, K.; Liu, Z. Functional nanomaterials for phototherapies of cancer. Chem. Rev. 2014, 114, 10869-10939. [CrossRef] [PubMed]

184. Erickson, T.A.; Tunnell, J.W. Gold nanoshells in biomedical applications. In Nanomaterials for the Life Sciences; Kumar, C.S.S.R., Ed.; Wiley-Vch Verlag Gmbh \& Co.: Weinheim, Germany, 2009; Volume 3.

185. Torchi, A.; Simonelli, F.; Ferrando, R.; Rossi, G. Local enhancement of lipid membrane permeability induced by irradiated gold nanoparticles. ACS Nano 2017, 11, 12553-12561. [CrossRef] [PubMed]

186. Skrabalak, S.E.; Chen, J.; Au, L.; Lu, X.; Li, X.; Xia, Y. Gold nanocages for biomedical applications. Adv. Mater. 2007, 19, 3177-3184. [CrossRef] [PubMed]

187. Alvarez-Paneque, A.F.; Rodríguez-González, B.; Pastoriza-Santos, I.; Liz-Marzán, L.M. Shape-templated growth of Au@Cu nanoparticles. J. Phys. Chem. C 2013, 117, 2474-2479. [CrossRef]

188. Kuznetsov, A.A.; Leontiev, V.G.; Brukvin, V.A.; Vorozhtsov, G.N.; Kogan, B.Y.; Shlyakhtin, O.A.; Yunin, A.M.; Tsybin, O.I.; Kuznetsov, O.A. Local radiofrequency-induced hyperthermia using CuNi nanoparticles with therapeutically suitable curie temperature. J. Magn. Magn. Mater. 2007, 311, 197-203. [CrossRef]

189. Shi, S.; Zhu, X.; Zhao, Z.; Fang, W.; Chen, M.; Huang, Y.; Chen, X. Photothermally enhanced photodynamic therapy based on mesoporous Pd@Ag@mSiO 2 nanocarriers. J. Mater. Chem. B 2013, 1, 1133-1141. [CrossRef]

190. Shin, S.; Song, I.; Um, S. Role of physicochemical properties in nanoparticle toxicity. Nanomaterials 2015, 5, 1351-1365. [CrossRef] [PubMed]

191. Mcnamara, K.; Tofail, S.A.M. Nanosystems: The use of nanoalloys, metallic, bimetallic, and magnetic nanoparticles in biomedical applications. Phys. Chem. Chem. Phys. 2015, 17, 27981-27995. [CrossRef] [PubMed]

192. Pankhurst, Q.A.; Thanh, N.K.T.; Jones, S.K.; Dobson, J. Progress in applications of magnetic nanoparticles in biomedicine. J. Phys. D Appl. Phys. 2009, 42, 224001-224015. [CrossRef]

193. Obaidat, I.; Issa, B.; Haik, Y. Magnetic properties of magnetic nanoparticles for efficient hyperthermia. Nanomaterials 2015, 5, 63-89. [CrossRef] [PubMed]

194. Gazeau, F.; Lévy, M.; Wilhelm, C. Optimizing magnetic nanoparticle design for nanothermotherapy. Nanomedicine 2008, 3, 831-844. [CrossRef] [PubMed] 
195. Wilczewska, A.Z.; Niemirowicz, K.; Markiewicz, K.H.; Car, H. Nanoparticles as drug delivery systems. Pharmacol. Rep. 2012, 64, 1020-1037. [CrossRef]

196. Suri, S.S.; Fenniri, H.; Singh, B. Nanotechnology-based drug delivery systems. J. Occup. Med. Toxicol. 2007, 2, 16. [CrossRef] [PubMed]

197. Kang, B.; Afifi, M.M.; Austin, L.A.; El-Sayed, M.A. Exploiting the nanoparticle Plasmon effect: Observing drug delivery dynamics in single cells via Raman/fluorescence imaging spectroscopy. ACS Nano 2013, 7, 7420-7427. [CrossRef] [PubMed]

198. Liu, K.; Bai, Y.; Zhang, L.; Yang, Z.; Fan, Q.; Zheng, H.; Yin, Y.; Gao, C. Porous Au-Ag nanospheres with high-density and highly accessible hotspots for SERS analysis. Nano Lett. 2016, 16, 3675-3681. [CrossRef] [PubMed]

199. Wu, W.; Shen, J.; Gai, Z.; Hong, K.; Banerjee, P.; Zhou, S. Multi-functional core-shell hybrid nanogels for $\mathrm{pH}$-dependent magnetic manipulation, fluorescent $\mathrm{pH}$-sensing, and drug delivery. Biomaterials 2011, 32, 9876-9887. [CrossRef] [PubMed]

(C) 2018 by the authors. Licensee MDPI, Basel, Switzerland. This article is an open access article distributed under the terms and conditions of the Creative Commons Attribution (CC BY) license (http://creativecommons.org/licenses/by/4.0/). 